University of Nebraska - Lincoln

DigitalCommons@University of Nebraska - Lincoln

Papers in Plant Pathology

Plant Pathology Department

2003

Unusual Life Style of Giant Chlorella Viruses

James L. Van Etten

University of Nebraska-Lincoln, jvanetten1@unl.edu

Follow this and additional works at: https://digitalcommons.unl.edu/plantpathpapers

Part of the Plant Pathology Commons

Van Etten, James L., "Unusual Life Style of Giant Chlorella Viruses" (2003). Papers in Plant Pathology. 197.

https://digitalcommons.unl.edu/plantpathpapers/197

This Article is brought to you for free and open access by the Plant Pathology Department at DigitalCommons@University of Nebraska - Lincoln. It has been accepted for inclusion in Papers in Plant Pathology by an authorized administrator of DigitalCommons@University of Nebraska - Lincoln. 


\title{
Unusual Life Style of Giant Chlorella Viruses
}

\section{James L. Van Etten}

Nebraska Center for Virology and Department of Plant Pathology, University of NebraskaLincoln, Lincoln, Nebraska 68583-0722; email jvanetten@unlnotes.unl.edu

\begin{abstract}
Paramecium bursaria chlorella virus (PBCV-1) is the prototype of a family of large, icosahedral, plaque-forming, dsDNA viruses that replicate in certain unicellular, eukaryotic chlorella-like green algae. Its 330-kb genome contains $\sim 373$ protein-encoding genes and 11 tRNA genes. The predicted gene products of $\sim 50 \%$ of these genes resemble proteins of known function, including many that are unexpected for a virus, e.g., ornithine decarboxylase, hyaluronan synthase, GDP-D-mannose 4,6 dehydratase, and a potassium ion channel protein. In addition to their large genome size, the chlorella viruses have other features that distinguish them from most viruses. These features include: $(a)$ The viruses encode multiple DNA methyltransferases and DNA site-specific endonucleases. $(b)$ The viruses encode at least some, if not all, of the enzymes required to glycosylate their proteins. (c) PBCV-1 has at least three types of introns, a self-splicing intron in a transcription factorlike gene, a spliceosomal processed intron in its DNA polymerase gene, and a small intron in one of its tRNA genes. (d) Many chlorella virus-encoded proteins are either the smallest or among the smallest proteins of their class. (e) Accumulating evidence indicates that the chlorella viruses have a very long evolutionary history.
\end{abstract}

Keywords: chlorella viruses, PBCV-1, algal viruses, protein glycosylation, ion channel proteins

\section{Contents}

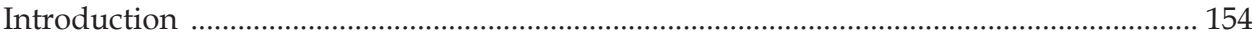

Classification of Chlorella Viruses and Their Hosts ...............................................................156

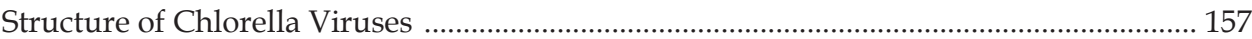

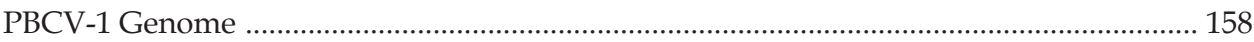

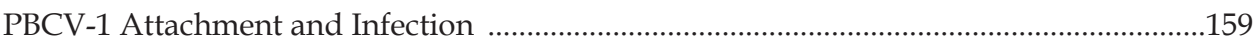

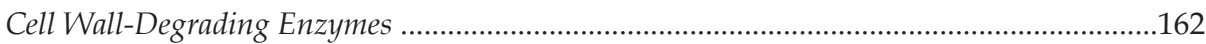

PBCV-1 DNA Replication, Recombination, Repair, and Methylation ............................... 163

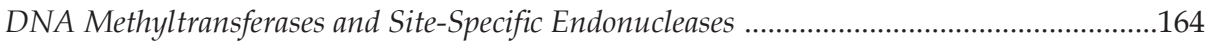

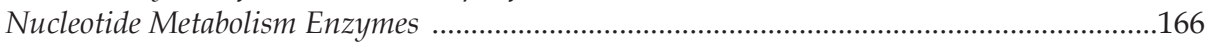

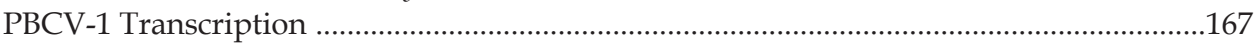

Set Domain-Containing Protein .......................................................................................168 


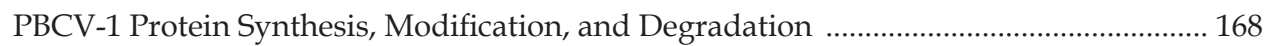

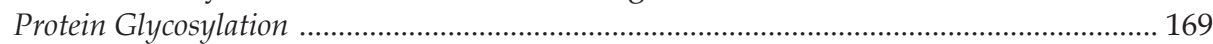

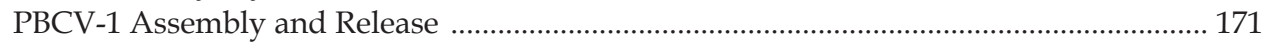

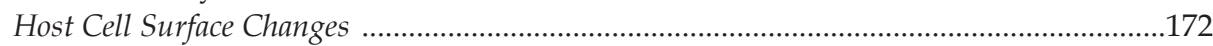

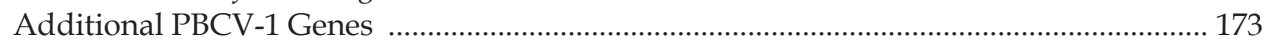

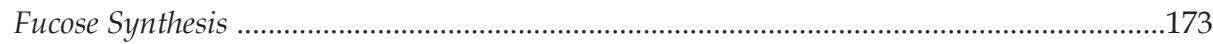

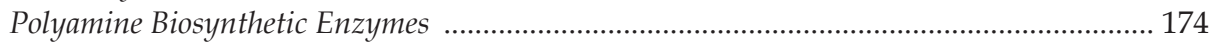

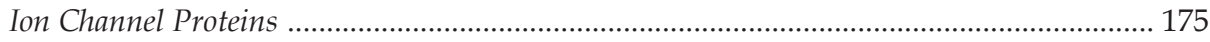

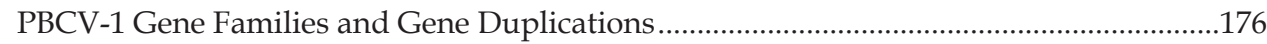

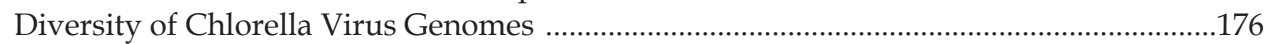

Natural History of the Chlorella Viruses ...............................................................................178

Other Phycodnaviruses and Putative Phycodnaviruses ..................................................... 181

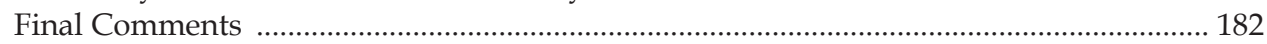

\section{Introduction}

Typically, one thinks of viruses as containing small genomes that encode only a few genes. However, several families of viruses have large dsDNA genomes that encode many proteins (Table 1). Examples include bacteriophage $G$ that infects Bacillus megaterium and has a genome of $\sim 670 \mathrm{~kb}(77)$, phycodnaviruses and putative phycodnaviruses that infect eukaryotic algae and have genomes up to $560 \mathrm{~kb}$

Table 1. Representative large dsDNA viruses

\begin{tabular}{|c|c|c|c|c|c|c|}
\hline Virus $^{\mathrm{a}}$ & Virus family & Host & $\begin{array}{l}\text { Genome } \\
\text { size (bp) }\end{array}$ & $\begin{array}{l}\text { Minimum } \\
\text { no. of } \\
\text { codons }^{b}\end{array}$ & $\begin{array}{l}\text { No. of } \\
\text { protein- } \\
\text { encoding } \\
\text { genes }\end{array}$ & Reference \\
\hline Phage G & Myoviridae & Bacillus megaterium & $-670,000$ & - & - & (77) \\
\hline PBCV-1 & Phycodnaviridae & Chlorella NC64A & 330,744 & 65 & 373 & (105) \\
\hline WSV & Unclassified & Shrimp & 292,967 & 51 & 184 & (215) \\
\hline MsEPV & Poxviridae & Grasshopper & 236,120 & 60 & 267 & (1) \\
\hline $\mathrm{MCV}$ & Poxviridae & Human & 190,289 & 60 & 182 & (173) \\
\hline ASFV & Asfarviridae & Swine & 170,101 & 60 & 151 & $(238)$ \\
\hline Phage T4 & Myoviridae & E. coli & 168,903 & 29 & 289 & $(124)$ \\
\hline HSV-2 & Herpesviridae & Human & 154,746 & - & $74^{\mathrm{c}}$ & (37) \\
\hline AcNPV & Baculoviridae & Insects & 133,894 & 50 & 154 & (4) \\
\hline LCDV & Iridoviridae & Flounder & 102,653 & 40 & 110 & (198) \\
\hline
\end{tabular}

a G, Giant; PBCV-1, Paramecium bursaria chlorella virus 1; WSV, white spots virus; MsEPV, Melanoplus sanguinipes entomopoxvirus; MCV, Molluscum contagiosum virus; ASFV, African swine fever virus; HSV-2, Herpes simplex virus type 2; AcNPV, Autographa californica multinucleocapsid nuclear polyhedroses virus; LCDV, lymphocystis disease virus.

b Minimum number of codons used by the authors to calculate an open reading frame (ORF).

c HSV-2 has 473 met-initiated ORFs of 50 codons or longer of which 74 are known to be functional genes. 
$(203,207)$, and some insect poxviruses with genomes as large as $365 \mathrm{~kb}(96)$. Other large, dsDNA-containing viruses, such as white spot virus (WSV) (215), herpesviruses (37), African swine fever virus (ASFV) (238), coliphage T4 (124), baculoviruses (4), and iridoviruses (198), have genomes ranging from 100 to $235 \mathrm{~kb}$. With the exception of bacteriophage $\mathrm{G}$, the genome of at least one representative from each of these dsDNA-containing viruses has been sequenced. The number of putative protein-encoding genes in these viruses range from 74 for the 154-kb herpes simplex virus-2 (HSV-2) to $\sim 373$ for the $330-\mathrm{kb}$ phycodnavirus Paramecium bursaria chlorella virus (PBCV-1).

To put the size of these viral genomes into perspective, the smallest bacterium, Mycoplasma genitalium, encodes 470 proteins and estimates of the minimum genome size required to support life are $\sim 250$ protein-encoding genes $(78,133)$. A recent comparative analysis of protein sequences encoded by poxviruses, ASFV, iridoviruses, and phycodnaviruses identified 9 genes that are shared by all of these viruses and 19 more genes that are present in at least three of these viral families (79). Cladistic analysis, using the genes shared by at least two viral families as evolutionary characters, led Iyer et al. (79) to propose that viruses in all four families arose from a common ancestor. However, there are significant differences among these four groups of viruses (207), and the common ancestor would have been ancient.

In addition to their large genomes, chlorella viruses have other distinctive features: (a) they encode multiple type II DNA methyltransferases and DNA sitespecific (restriction) endonucleases $(142,143)$. (b) Unlike other glycoproteincontaining viruses, chlorella viruses encode most, if not all, of the components required to glycosylate their proteins $(58,219)$. (c) Chlorella viruses are the first viruses discovered with more than one type of intron. Three types of introns have been described in PBCV-1: a self-splicing intron in a transcription factor TFIISlike gene $(104,236)$, a spliceosomal-processed intron in the DNA polymerase gene $(57,239)$, and a small intron in one of the tRNA genes (145). (d) Many chlorella virus-encoded proteins are either the smallest or among the smallest proteins of their class and some may represent the minimal catalytic unit. In addition, genes shared by chlorella virus isolates can differ in nucleotide sequence by as much as $40 \%$; proteins can differ in amino acid sequence by $35 \%$. Therefore, comparative gene sequence analyses can identify conserved amino acids in proteins, as well as regions that tolerate amino acid changes. The small sizes and the finding that many virus-encoded recombinant proteins are "laboratory friendly" have resulted in the biochemical and structural characterization of several PBCV1 enzymes. Examples include: (a) The smallest known eukaryotic ATP-dependent DNA ligase (75), which is the subject of intensive mechanistic and structural studies (183 and references cited therein). (b) The smallest known type II DNA topoisomerase (99). The PBCV-1 enzyme cleaves dsDNAs 30 times faster than the human type II DNA topoisomerase $(46,47)$; consequently, the virus enzyme is a model to study topoisomerase II DNA cleavage. (c) An RNA capping guanylyltransferase (74) that was the first enzyme of its type to have its crystal structure resolved $(62,63)$. (d) The smallest known protein (94 amino acids) to form a func- 
tional $\mathrm{K}^{+}$channel (153). (e) The smallest enzyme (120 amino acids) known to posttranslationally modify histone proteins by methylating histone $\mathrm{H} 3$ at Lys ${ }^{27}$ (115).

The history and ecological aspects of algal viruses can be found in other reviews $(35,101,132,178,190,207-209,224)$. This review focuses mainly on the properties of the chlorella viruses, primarily PBCV-1. More information, including a complete list of chlorella virus publications and additional images of the viruses, is available on the "World of Chlorella Viruses" web page at http:/ / www. ianr.unl.edu/plantpath/facilities/Virology .

\section{Classification of Chlorella Viruses and Their Hosts}

It is difficult to credit the first person to mention chlorella viruses. A few papers in the Russian literature more than 40 years ago describe a lytic activity in cultures of Chlorella pyrenoidosa (see 208). However, the cultures were contaminated with bacteria and the viruses pictured have bacteriophage morphology. In 1978, Kawakami \& Kawakami (86) described the appearance of large, lytic viruses in chlorella after the algae were released from the protozoan Paramecium bursaria, but no virus particles were detected in chlorella growing symbiotically inside the paramecium. Independently, lytic viruses were described in chlorella isolated from the green coelenterate Hydra viridis $(122,210)$ and also from P. bursaria (211). As in the 1978 report, viruses appeared only after the chlorella were separated from their hosts. Fortunately for the experimental biologist, the chlorella from $P$. bursaria can be grown free of the paramecium in culture, and ensuing experiments have revealed that these cultured algae are hosts for what have become known as the chlorella viruses. The one disadvantage to studying these viruses has been the inability to develop molecular procedures to manipulate the virus genome. To date all attempts to transform the host chlorella have been unsuccessful.

Chlorella viruses are large (1900 ̊ along the fivefold axes), icosahedral, plaque-forming, dsDNA viruses that infect certain unicellular, chlorella-like green algae. The chlorella viruses are included in the genus Chlorovirus that consists of three species (203). (a) Viruses that infect Chlorella isolate NC64A (NC64A viruses). (b) Viruses that infect Chlorella Pbi (Pbi viruses). (c) Viruses that infect symbiotic chlorella in the coelenterate Hydra viridis. This latter chlorella host has not been cultured free of the virus and consequently, the virus can be isolated only from chlorella cells freshly released from hydra.

Algae included in the genus Chlorella are small spherical or ellipsoidal, unicellular, nonmotile, asexually reproducing green algae and are among the most widely distributed and frequently encountered algae on earth $(148,177)$. Chlorella species have a rigid cell wall and typically have a single chloroplast, which sometimes contains a pyrenoid body. They have a simple developmental cycle and reproduce by mitotic division. Vegetative cells increase in size and, depending on the species and environmental conditions, divide into two, four, eight, or 
more progeny, which are released by rupture or enzymatic digestion of the parental walls. Electrophoretic karyotyping of several chlorella isolates, including Chlorella NC64A, indicates that the algae have multiple chromosomes ranging in size from $\sim 1 \mathrm{mb}$ to $\sim 6.5 \mathrm{mb}$, with a total genome size of $\sim 40 \mathrm{mb}(70,116)$.

However, algae assigned to the genus Chlorella are more heterogeneous than their simple morphology suggests. Because of this diversity, properties discovered in one Chlorella species or isolate may not apply to another species. Two examples illustrate the degree of heterogeneity. (a) The G+C contents of the nuclear DNAs of Chlorella species range from $43 \%$ to $79 \%$ (67). However, most isolates assigned to the same species have similar G+C contents. The PBCV-1 host, Chlorella NC64A, has a G+C content of $67 \%$. The genome of Chlorella NC64A also contains methylated nucleotides; $21 \%$ of the cytosines are 5-methylcytosine $(\mathrm{m} 5 \mathrm{C})$ and $0.6 \%$ of the adenines are N6-methyladenine (m6A) (212). (b) The cell wall polysaccharides of Chlorella species vary widely $(108,194,235)$, even among isolates assigned to the same species (235). Unexpectedly, lipopolysaccharide (LPS)-like components were discovered recently in the cell walls of some chlorella isolates (167). This finding was a surprise because LPS is typically only found in Gram-negative bacteria.

Most chlorella species are naturally free-living. However, some live as hereditary endosymbionts (also referred to as zoochlorella) within freshwater and, to lesser extent, marine animals $(160,200)$. The only known hosts for the chlorella viruses are symbiotic chlorella, some of which can be cultured.

\section{Structure of Chlorella Viruses}

Chlorella virus particles are complex (molecular weight $\sim 1 \times 10^{9} \mathrm{Da}$ ) and the PBCV-1 virion contains $\sim 50$ different proteins (180), including several that bind DNA (231). The PBCV-1 54-kDa major capsid protein Vp54 is a glycoprotein and comprises $\sim 40 \%$ of the virus protein. Vp54 consists of two eight-stranded, antiparallel $\beta$-barrel, jelly-roll domains related by a pseudo-sixfold rotation (140). The major capsid proteins from many viruses have a similar jelly-roll structure including those from dsDNA bacterial (e.g., PRD1) and animal viruses (e.g., adenoviruses) $(140,166)$. This structural similarity belies a lack of amino acid identity in many of these capsid proteins.

Cryo-electron microscopy (cryoEM) and three-dimensional (3D) image reconstruction of PBCV-1 (26 ̊ resolution) indicate that the outer glycoprotein capsid is icosahedral and surrounds a lipid bilayer membrane (Figure 1A,B [page 197]) (237). The membrane, which contains phosphatidyl choline and phosphatidyl ethanolamine, is required for infectivity because the virus loses infectivity rapidly in chloroform and more slowly in ethyl ether or toluene (180). The membrane is connected to the outer shell by regularly spaced proteins (Figure 1C). The outer diameter of the viral capsid varies from a minimum of $1650 \AA$ along the two- and threefold axes to a maximum of $1900 \AA$ along the fivefold axes. The capsid shell consists of 1680 donut-shaped trimeric capsomers plus 12 pentameric capsomers 
at each icosahedral vertex. The trimeric capsomers are arranged into 20 triangular facets (trisymmetrons, each containing 66 trimers) and 12 pentagonal facets (pentasymmetrons, each containing 30 trimers and one pentamer at the icosahedral vertices) (Figure $1 A$ ). Assuming all the trimeric capsomers are identical (but see below), the outer capsid of the virus contains 5040 copies of the major capsid protein Vp54. The triangulation number (T) for the virus is 169 and the virus has a right-handed, skew class of $\mathrm{T}$ lattice (16).

Most of the trimeric capsomers have a central, concave depression surrounded by three protruding towers. The trimeric capsomers are $72 \AA$ in diameter and $\sim 75$ $\AA$ high. The prominent, cylinder portion of each trimer extends $\sim 50 \AA$ above the surface of the capsid shell. The capsomers interconnect at their bases in a contiguous shell that is 20-25 $\AA$ thick. Within each trimer, the three monomers connect in

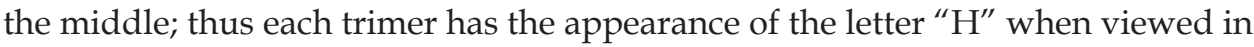
cross section (Figure 1D). This structure agrees with the Vp54 structural studies (140). Cross-sectional views of 3D reconstructions at $20 \AA$ resolution reveal a "cement" protein(s) that connects the bases of the trimeric capsomers (arrow in Figure 1D) (X. Yan, V. Bowman, N. H. Olson, M. V. Graves, L. C. Lane, M. G. Rossmann, J. L. Van Etten \& T. S. Baker, manuscript in preparation).

Twelve pentamer capsomers, each $\sim 70 \AA$ in diameter, exist at the fivefold vertices of the virus and probably consist of a different protein. Each pentamer is surrounded by radially distributed trimers, and the axis of each of these trimers tilts away from the pentamer. Each pentamer has a cone-shaped, axial channel at its base (Figure $1 E$ ). One or more proteins appear below the axial channel and outside the inner membrane (Figure $1 E$ ). This protein(s) may digest the host cell wall during infection. Presumably, contact between the virus and its host receptor alters the channel sufficiently to release the cell wall-degrading enzyme(s).

Stereo views indicate that PBCV-1 attaches to the host cell wall by hair-like fibers that originate from the virus particle (208). Similar views of isolated virus particles suggest that the fibers are flexible with terminal swollen structures. Although 3D reconstructions of PBCV-1 at $26 \AA$ resolution suggested that all the capsomers in the virion trisymmetrons were identical (237), more refined PBCV-1 $3 \mathrm{D}$ reconstructions reveal additional surface features (Figure $1 F$ ). Three regularly spaced trimeric capsomers in each PBCV-1 trisymmetron have an oval-shaped structure that resembles the top of a mushroom (Figure 1D,F). We suspect that these structures and the hair-like fibers mentioned above are related. Our interpretation of these results is that the hair-like fibers exist as coiled "springs" in the virion and that the fibers extend when they contact the host.

\section{PBCV-1 Genome}

The PBCV-1 genome consists of a linear 330,744-bp, nonpermuted dsDNA molecule with covalently closed hairpin termini $(154,165)$. The termini consist of 35-nucleotide-long, incompletely base-paired, covalently closed hairpin loops that exist in one of two forms; the two forms are complementary when the 35-nucleo- 
tide sequences are inverted (flip-flop) (243). Identical 2221-bp inverted repeats are adjacent to each hairpin end (184). The remainder of the PBCV-1 genome contains primarily single-copy DNA (54). PBCV-1 and all other NC64A virus genomes are $\sim 40 \%$ G + C. Yamada \& Higashiyama (232) suggested that the inverted repeat region of another chlorella virus, CVK1, contains a site-specific nick. If so, this nick could serve as an initiation point for DNA replication.

The PBCV-1 genome contains methylated nucleotides. For example, 1.9\% of the cytosines are $\mathrm{m} 5 \mathrm{C}$ and $1.5 \%$ of the adenines are m6A (212). In fact, the genomes of all the chlorella viruses have methylated bases and the viruses can be distinguished from one another by the site-specificity and amount of DNA methylation $(142,143,208)$.

The sequence of the PBCV-1 genome revealed 697 ORFs of 65 codons or larger. About 373 of these ORFs probably encode proteins (92, 104, 105, 110, 111). Initially, PBCV-1 protein-encoding genes were identified by the following criteria: (a) A minimal size of 65 codons initiated by an ATG codon. (b) The largest ORF was chosen when competing ORFs overlapped. (c) ORFs with AT-rich (>70\%) sequences in the 50 nucleotides upstream of the putative initiation codons. To date, all protein-encoding genes have met these criteria.

Unlike the poxviruses, in which genes near the terminal regions are transcribed toward the termini (130), the 373 putative protein-encoding genes are evenly distributed on both strands and, with one exception, intergenic space is minimal. In fact, 275 ORFs are separated by less than 100 nucleotides. The exception is a 1788-nucleotide sequence near the middle of the genome. This DNA region, which contains many stop codons in all reading frames, encodes 11 tRNA genes. In addition, 900 nucleotides in this region have two properties characteristic of CpG islands (2). (a) The region has greater than $60 \% \mathrm{G}+\mathrm{C}$, whereas the flanking regions contain less than $40 \% \mathrm{G}+\mathrm{C}$. (b) The observed-to-expected ratio of CpG dinucleotides is $1.45(50,98)$. The 2.2-kb inverted terminal repeat region of the PBCV-1 genome contains 4 ORFs; these 4 ORFs are duplicated $(111,184)$.

Approximately $50 \%$ of the 373 PBCV-1 gene products have been tentatively identified, including some that seem irrelevant to virus replication. Some PBCV1 genes are closely related to genes of bacteria and their viruses, whereas other PBCV-1 genes appear eukaryotic in origin. Some PBCV-1-encoded enzymes can be assembled into metabolic pathways, e.g., hyaluronan synthesis (Figure $2 A$ ), fucose synthesis (Figure 2B), and polyamine synthesis (Figure 2C). Surprisingly, given the large number of PBCV-1 genes, the virus lacks a recognizable RNA polymerase gene. Therefore, PBCV-1 must depend on host enzymes for transcription.

\section{PBCV-1 Attachment and Infection}

PBCV-1 infects its host Chlorella NC64A by attaching rapidly, possibly by the hairlike fibers mentioned above, to the algal cell wall (120). The virus then contacts the cell wall via one of its vertices, presumably producing a conformational change in the virus, which leads to the release of a precise amount of cell wall- 


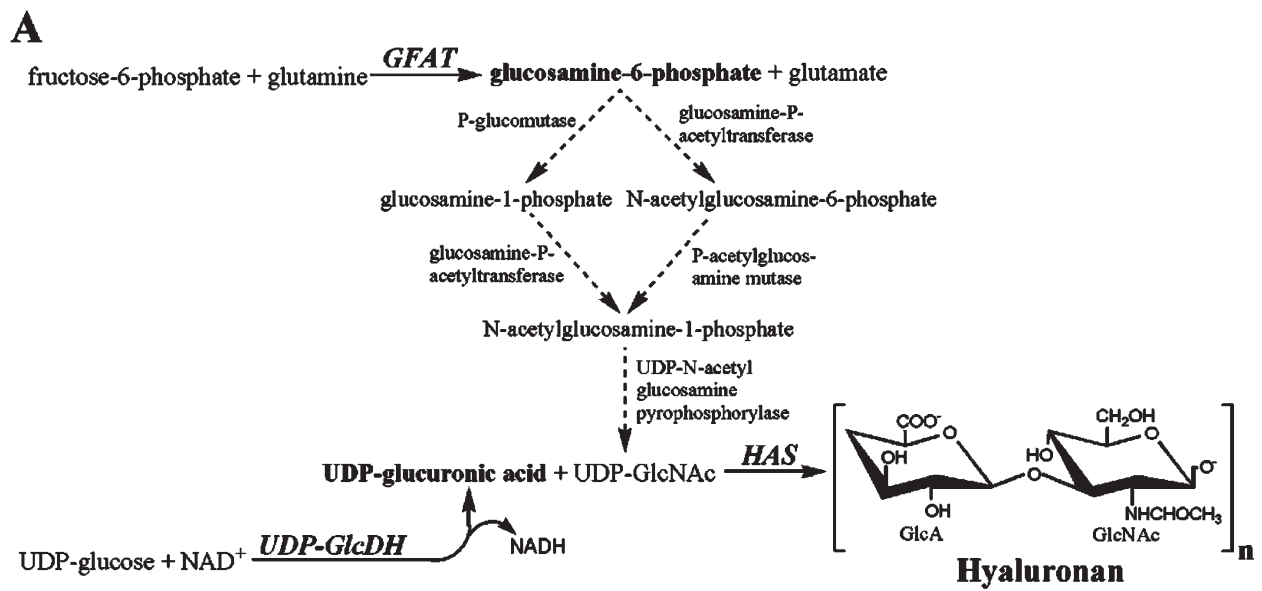

B
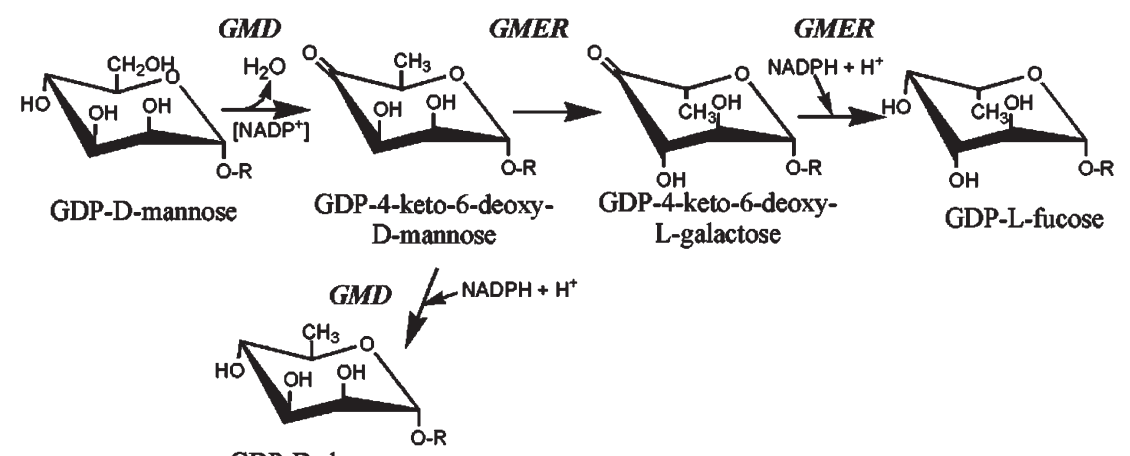

C

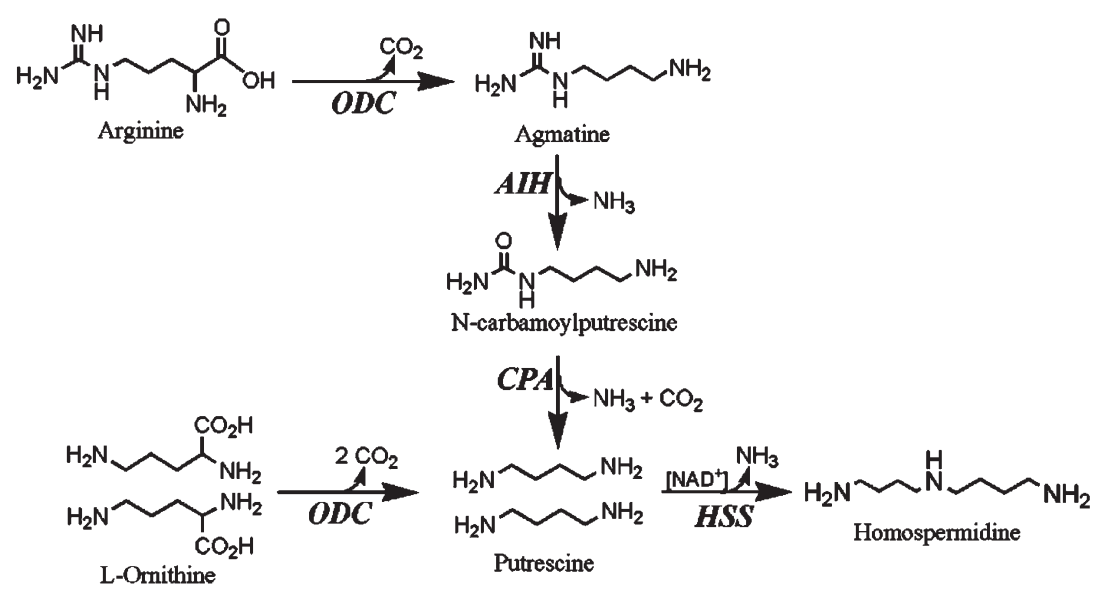


digesting enzyme(s). Following digestion of the wall, the internal membrane of PBCV-1 presumably fuses with the host membrane to translocate virus DNA and probably associated proteins (e.g., transcription factors?) to the inside of the host, leaving an empty capsid on the surface.

The virus also attaches to and digests cell-free wall fragments that have been boiled or extracted by harsh procedures, supporting the conclusion that the walldegrading enzymes(s) are packaged in the virus particles $(120,163)$. Release of virus DNA requires a host function because virus attachment and digestion of isolated walls does not release DNA. Experiments to identify the virus receptor in Chlorella NC64A indicate that it is probably a carbohydrate (119).

Two observations suggest that the infecting PBCV-1 DNA and probably DNA-associated proteins quickly move to the nucleus and commandeer at least some of the host transcription machinery to initiate early viral RNA synthesis; early virus transcripts can be detected within 5-10 min post infection (p.i.). (a) PBCV-1 does not encode a recognizable RNA polymerase gene(s) nor were we able to detect RNA polymerase activity in isolated virions (J. Rohozinski \& J. L. Van Etten, unpublished results). (b) A small intron with splice-site sequences characteristic of nuclear-spliced mRNAs exists in the PBCV-1 DNA polymerase gene (57). Presumably, this intron would need to be excised in the infected cell nucleus.

Ultrastructural studies indicate that an apparently intact nuclear membrane often can be seen in infected cells, at least during early stages of virus replication (121). However, virus replication does not require a functional host nucleus because PBCV-1 replicates, albeit slowly and with a small burst size, in UV-irradiated cells; such cells are unable to form colonies and endogenous RNA and DNA

Figure 2. (page 160) Unexpected biosynthetic pathways encoded by chlorella virus PBCV-1. A. Hyaluronan: PBCV-1 contains genes that encode three enzymes involved in hyaluronan biosynthesis, glucosamine synthase (GFAT), UDP-glucose dehydrogenase (UDP-GlcDH), and hyaluronan synthase (HAS). B. GDP-L-fucose and GDP-D-rhamnose: The virus encodes GDP-D-mannose 4,6 dehydratase (GMD), which catalyzes both the dehydration of GDP-D-mannose to the intermediate GDP-4-keto-6-deoxy-D-mannose and the NADPH-dependent reduction of this latter compound to GDP-D-rhamnose. GDP-4-keto-6-deoxy-D-mannose epimerase/ reductase(GMER)catalyzes the final two steps to GDP-L-fucose. C. Polyamines: PBCV1 encodes the enzymes for two pathways to make putrescine. Ornithine decarboxylase (ODC) converts ornithine directly to putrescine. However, the same ODC also decarboxylates arginine to agmatine (A. E. Pegg, personal communication). PBCV-1 also encodes the two enzymes [agmatine iminohydrolase (AIH) and N-carbamoylputrescine amidohydrolase (CPA)], that convert agmatine to putrescine (M. Piotrowski, personal communication). Finally, the virus encodes homospermidine synthase that converts two putrescines to homospermidine. The PBCV-1-encoded enzymes are in bold. Recombinant proteins have been produced for each of these enzymes and shown to be biochemically active. 
syntheses are reduced to background levels (205). PBCV-1 replication also does not require labile host factors since the virus replicates in UV-inactivated cells incubated in the dark for up to $8 \mathrm{~h}$ before infection.

PBCV-1 DNA replication begins 60-90 min p.i., presumably in the nucleus, and is followed by transcription of late virus genes $(170,204)$. Progeny viruses are first released $4-5 \mathrm{~h}$ p.i. and the majority of infectious virus particles are released by $8 \mathrm{~h}$ p.i. via localized lysis of the cell wall. The virus has a burst size of 200 to 350 plaqueforming units (PFU); $25 \%$ to $50 \%$ of the released virions form plaques (206).

Mechanical disruption of the cells releases infectious virus 30 to 50 min prior to spontaneous lysis. Thus, infectious PBCV-1 is assembled inside the host and does not acquire its membrane and glycoprotein capsid by budding through an exterior host membrane. PBCV-1 also replicates in dark-grown chlorella cells or in light-grown cells treated with the photosynthetic inhibitor DCMU prior to virus infection (206). In both situations the time course of virus release is similar to that of untreated light-grown cells, which implies that PBCV-1 replication does not require host photosynthesis. However, the burst size is reduced $\sim 50 \%$ in darkgrown cells. PBCV-1 infection rapidly inhibits host $\mathrm{CO}^{2}$ fixation $(172,206)$. Like most bacterial viruses (64), PBCV-1 replicates most efficiently in actively growing host cells and poorly in stationary-phase cells.

The infection process of the chlorella viruses differs from that of all DNA viruses known to infect eukaryotes, but resembles that of bacterial viruses in that uncoating occurs at the cell surface. In terms of structure (e.g., an internal membrane and the major capsid protein), attachment, and penetration, the chlorella viruses resemble bacteriophages of the Tectiviridae family $(5,125)$. However, tectiviruses are much smaller ( $650 \AA$ in diameter) with a 40-kd genome.

\section{Cell Wall-Degrading Enzymes}

PBCV-1 and another NC64A virus (CVK2) encode several enzymes that could aid in host cell wall degradation either during virus infection or virus release. These enzymes include two chitinases, a chitosanase, a $\beta$-1,3-glucanase, and another enzyme that partially degrades NC64A cell walls. Recombinant proteins produced from these five genes have the expected enzyme activities (71, 72, 185-188, 234). Enzymes packaged in the virion and involved in virus infection are expected to be expressed late in the infection cycle. One of the chitinases and the chitosanase meet this requirement and are packaged in the PBCV-1 virion. However, the $\beta-1,3-$ glucanase is expressed early in infected cells and the protein disappears by $90 \mathrm{~min}$ p.i., i.e., before virus assembly and host cell lysis (188). Incubation of host cells with all five recombinant enzymes does not produce algal protoplasts, indicating that cell wall degradation requires at least one additional enzyme activity. In contrast, a crude enzyme extract made from virus lysates, called lysin, completely digests Chlorella NC64A cell walls (119; R. H. Meints, unpublished results).

The chitosanase gene, which is expressed late in infection, has been characterized from virus CVK2 (234). The CVK2 gene encodes two proteins with chi- 
tosanase activity, a 37-kDa protein of the expected size from the DNA gene sequence and a $65-\mathrm{kDa}$ protein. The larger protein is packaged in nascent virions, whereas the smaller protein occurs only in infected cells. Interestingly, PBCV-1 contains the same chitosanase gene flanked by two ORFs common to virus CVK2. However, CVK2 has an extra ORF inserted immediately downstream of its chitosanase gene, which contributes to the bigger 65-kDa protein, presumably as a read-through product.

The discovery of chitinase and chitosanase genes in the chlorella viruses was initially unexpected because chitin is rare in algae (69). Chitin is a normal component of fungal cell walls and the exoskeleton of insects and crustaceans (56). However, chitin or chitin-like material has been reported in cell walls of some chlorella species (195), including Chlorella Pbi $(84,85)$ and possibly Chlorella NC64A. Support for this possibility is that $\sim 10 \%$ of the component monosaccharides in Chlorella NC64A cell walls is glucosamine (119). Glucose and rhamnose make up $51 \%$ and $16 \%$ of the total sugars, respectively, in Chlorella NC64A walls, with galactose, xylose, arabinose, and mannose each accounting for $5 \%$ to $10 \%$ of the sugars. Trace amounts of fucose have also been detected in Chlorella NC64A walls.

\section{PBCV-1 DNA Replication, Recombination, Repair, and Methylation}

PBCV-1 encodes at least 10 putative proteins involved in either DNA replication or recombination. Presumably, these genes are transcribed in the nucleus, translated in the cytoplasm and then returned to the nucleus to initiate virus DNA synthesis, which begins at 60-90 min p.i. The PBCV-1 DNA polymerase enzyme (57) belongs to the DNA polymerase- $\delta$ family (217) and contains a proof-reading 3'-5' exonuclease domain (76). PBCV-1 also encodes two sliding clamp processivity factor proteins (PCNA). The two viral PCNA proteins resemble PCNAs from other organisms more than they resemble each other $(26 \%$ amino acid identity), suggesting independent acquisition of the two genes rather than gene duplication. PCNA not only interacts with proteins involved in DNA replication, but proteins involved in DNA repair and post-replicative processing such as DNA methyltransferases and DNA transposases (220). Because PBCV-1 encodes proteins involved in DNA repair, DNA methylation, and a possible transposase, the two PCNAs may serve different functions in PBCV-1 replication.

A protein complex, called replication factor C (RFC) in Archae and eukaryotes, is responsible for the ATP-dependent loading of PCNA onto DNA $(41,131)$. RFCs from eukaryotes are heteropentamers. The clamp loading equivalent, called $\gamma$-complex, from bacteria also is a heteropentamer, whereas RFC complexes from Archae are heterodimers $(88,152)$. PBCV-1 encodes a single protein that resembles one of the two proteins that comprise Archae RFC (L. Fitzgerald, M. Griep, \& J. L. Van Etten, unpublished results). It is unknown if the PBCV-1 protein can function by itself as an RFC protein or requires other host proteins for activity. 
PBCV-1 also encodes other proteins involved in DNA replication including an ATP-dependent DNA ligase (75), an RNase H (J. L. Van Etten, unpublished results), and a type II DNA topoisomerase (99). The PBCV-1 topoisomerase II is smaller than other topoisomerase II enzymes, partially because it lacks a nuclear localization signal. The computer program PSORT, a cellular protein localization prediction program (139), predicts that the protein resides in the cytoplasm. If the topoisomerase II is in the cytoplasm and the host nucleus remains intact during virus replication, the enzyme may process viral DNA during packaging into nascent virions.

Thus PBCV-1 encodes genes for many of the essential elements of eukaryotic DNA replication, but does not have a full complement of DNA replication proteins and must partially rely on host enzymes. For example, PBCV-1 lacks a DNA primase encoding gene. Primase initiates synthesis of new DNA strands by synthesizing short RNA oligomers on ssDNA (3). However, PBCV-1 encodes a protein (ORF A456L) that displays amino acid sequence similarity to a special class of trifunctional primase-helicase-origin recognition proteins (M. Griep, personal communication). The helicase portion of the viral protein resembles the superfamily III helicases. Therefore, we predict that this viral protein participates in viral DNA replication.

PBCV-1 also encodes a 5'-3' exonuclease homolog (ORF A166R) that is probably involved in DNA recombination (18). Using PBCV-1 temperature-sensitive mutants, Tessman (197) established that genetic recombination occurs at a frequency of $\sim 2 \%$. Finally, PBCV-1 encodes a homolog of the bacteriophage T4 pyrimidine dimer-specific glycosylase (PDG), a well-characterized DNA repair enzyme involved in pyrimidine photodimer excision (49). Comparative studies with the T4 enzyme revealed that PBCV-1 PDG cleaves both cis-syn and trans-syn-II cyclobutane pyrimidine dimers, whereas the T4 enzyme only cleaves the cis-syn form (117). The PBCV-1 PDG also excises two other monomeric products induced by UV radiation or hydroxylradicals, 4,6-diamino-5-formamidopyrimidine and 2,6 diamino-4-hydroxy-5-formamidopyrimidine (81). The PBCV-1 PDG is more processive than the T4 enzyme and is the first trans-syn-II-specific glycosylase identified to date.

\section{DNA Methyltransferases and Site-Specific Endonucleases}

DNA from each of 37 chlorella viruses contains $\mathrm{m} 5 \mathrm{C}$ in amounts varying from $0.12 \%$ to $47.5 \%$ of the total cytosine. In addition, 24 of the 37 viral DNAs contain $\mathrm{m} 6 \mathrm{~A}$ in amounts varying from $1.5 \%$ to $37 \%$ of the total adenine $(142,212)$. At one end of the spectrum is a virus with $0.12 \% \mathrm{~m} 5 \mathrm{C}$ and no m6A and at the other end, a virus with $45 \% \mathrm{~m} 5 \mathrm{C}$ and $37 \% \mathrm{~m} 6 \mathrm{~A}$. Because these viruses differ greatly in DNA methylation, they offer a unique opportunity to study the effect of methylated bases on common enzymes and proteins, such as transcription factors, that interact with DNA.

The methylated bases occur in specific DNA sequences; thus it is not surprising that the chlorella viruses encode multiple m5C and m6A DNA methyltransferases (MTases). However, we were surprised to discover that $\sim 25 \%$ of the 
virus-encoded DNA MTases have a companion DNA site-specific (restriction) endonuclease. Thus, virus-infected chlorella are the first nonprokaryotic source of type II DNA restriction endonucleases (for reviews see 142, 143).

Some virus-encoded endonucleases have recognition and cleavage site specificities identical to bacterial type II restriction endonucleases [e.g., R.CviAI (/ GATC) (225)], others are heteroschizomers of bacterial endonucleases [e.g., R.CviAII (C/ATG) (240)], and still others have novel recognition sites [e.g., R.CviJI (RG/CY) (226)]. Statistically, R.CviJI recognizes a 3-bp sequence, and under certain reaction conditions, called R.CviJI* "star" conditions), the enzyme also cleaves RGCR and YGCY sequences $(44,193,226)$. Two of the chlorella virus site-specific endonucleases cleave only one strand of dsDNA [NYs1-nickase cleaves /CC sites (227) and NY2A-nickase cleaves R/AG sites (241)]. Like bacterial restriction endonucleases, viral endonucleases are inhibited by $\mathrm{m} 5 \mathrm{C}$ or $\mathrm{m} 6 \mathrm{~A}$ in their recognition sites.

A summary of other characteristics of the chlorella virus restriction-modification (R-M) systems follows: (a) Some viruses, e.g., NY-2A, encode as many as ten distinct DNA MTases (seven m6A MTases and three m5C MTases) and at least two site-specific endonucleases (241). (b) Viruses with high levels of methylated bases encode some MTases that recognize short (2- to 3-bp) target sites, e.g., M.CviPI from virus NYs-1 methylates GC sequences (229). (c) Like bacterial type II R-M genes (222), the chlorella virus R-M genes are located near one another, although the spacing and relative orientation of the two genes can vary. (d) The virus m6A- and m5C-MTases contain the same conserved amino acid motifs found in bacterial m6A MTases (114) and m5C MTases $(91,154)$. (e) In some instances the amino acid sequence of virus MTases with the same site-specificities differ by as much as $60 \%$, suggesting that the gene has either evolved extensively or been acquired by the viruses from more than one source (157).

The biological function(s) of the chlorella virus-encoded DNA site-specific endonucleases and MTases is unknown. Bacterial R-M systems confer resistance to foreign DNAs and DNA viruses. Two functions have been considered for the chlorella virus R-M enzymes. (a) The endonucleases help degrade host DNA, thus providing deoxynucleotides for incorporation into virus DNA. Methylation of nascent virus DNAs by the cognate MTases protects the DNA from self-digestion. (b) The endonucleases prevent infection of a cell by a second virus.

Several observations are consistent with the first hypothesis. (a) Host nuclear and chloroplast DNAs, but not virus DNA, are digested by virus-encoded sitespecific endonuclease(s) in vitro. (b) Host DNA degradation does not occur if cycloheximide is added at the time of virus infection (204), indicating that DNA degradation requires protein synthesis. (c) In vivo degradation of host nuclear and chloroplast DNAs coincides with the appearance of DNA site-specific endonuclease activity. (d) Initiation of virus DNA synthesis in vivo coincides with the appearance of DNA MTase activity $(225,228)$.

The isolation of three independently derived deletion mutants of virus IL-3A, which had lost their MTase (M.CviJI) and site-specific endonuclease (R.CviJI) ac- 
tivities, allowed us to test the host DNA degradation hypothesis (14). If CviJI activity was essential for host DNA degradation, nuclear and/or chloroplast DNA should be preserved or at least degraded more slowly in cells infected with the mutants than in cells infected with wild-type IL-3A. However, both nuclear and chloroplast DNA levels decreased at similar rates following infection with each of the four viruses (14). Therefore, CviJI activity was not essential for host DNA degradation. However, these results do not exclude participation of the enzyme in the degradation process.

To determine whether the endonuclease(s) excludes infection of a cell by a second virus, chlorella cells were dually inoculated with different viruses and plaques arising from infective centers were distinguished by immunoblotting (20). These experiments revealed that the chlorella viruses, like certain bacteriophages (see 36) exclude one another. However, this exclusion was independent of the site-specific endonuclease activities.

Therefore, the biological function of the DNA MTases and site-specific endonucleases remains unknown. However, if a virus encodes a functional cytosine MTase gene, then its expression is necessary for virus growth. There is a direct correlation between increasing $\mathrm{m} 5 \mathrm{C}$ concentrations in the virus genome and sensitivity of virus replication to the cytidine methylation inhibitor, 5-azacytidine (14).

PBCV-1, containing only $1.9 \% \mathrm{~m} 5 \mathrm{C}$ and $1.5 \% \mathrm{~m} 6 \mathrm{~A}$, encodes $7 \mathrm{R}-\mathrm{M}$ enzymes, including two R-M systems that involve m6A and three m5C MTases. Interestingly, one of these latter genes encodes an inactive enzyme that differs by 8 amino acids from M.CviJI from another virus. Domain swapping and site-directed mutations established that a single base change that creates a single amino acid substitution made the inactive enzyme active (242).

As discussed below, the natural history of the chlorella viruses is poorly understood. Presumably, the DNA MTases and endonucleases confer an evolutionary advantage to the viruses in their native environment.

\section{Nucleotide Metabolism Enzymes}

PBCV-1 DNA replication begins 60-90 min p.i. at the same time that host nuclear and chloroplast DNAs begin degrading (204). Total DNA in the cell increases four- to tenfold by $4 \mathrm{~h}$ p.i. due to viral DNA synthesis. Viral DNA synthesis requires large quantities of dNTPs that cannot be accounted for simply by recycling deoxynucleotides from host DNA. To guarantee a supply of deoxynucleotides in non-proliferating host cells, large DNA viruses frequently encode deoxynucleotide synthesis enzymes, including both subunits of ribonucleotide reductase. PBCV-1 encodes at least 13 nucleotide metabolic enzymes, aspartate transcarbamylase, both subunits of ribonucleotide reductase, dUTP pyrophosphatase, dCMP deaminase, thymidylate kinase, nucleotide triphosphatase, cytidine deaminase, thymidylate synthase, glutaredoxin, thioredoxin, and two ATPases.

Two of the PBCV-1-encoded enzymes, dUTP pyrophosphatase and dCMP deaminase, synthesize dUMP, the substrate for thymidylate synthetase. PBCV-1 lacks 
a traditional thymidylate synthetase A. Instead, PBCV-1 encodes a protein that is a member of a newly recognized family of flavin-dependent thymidylate synthetases called X (134). A thymidylate synthetase X encoding gene is also found in Dictyostelium (40) and in $\sim 25 \%$ of sequenced bacteria and Archae genomes (134).

\section{PBCV-1 Transcription}

PBCV-1 gene expression is temporally regulated and can be divided into two distinct stages, early and late. However, a few genes are transcribed both early and late (e.g., elongation factor 3 and ornithine decarboxylase). The junction between these stages is 60 to 90 min p.i., which coincides with the start of virus DNA synthesis. The incorporation of $\left[{ }^{3} \mathrm{H}\right]$-adenine into polyadenylated RNA also decreases abruptly at about $60 \mathrm{~min}$ p.i. Assuming this decrease is not due to dilution from a large increase in an ATP pool, we predict that polyadenylate segments are rare in late virus transcripts, but likely common in early virus transcripts (213).

Two studies $(170,171)$ have examined PBCV-1 RNA synthesis and the following general statements can be made about virus transcription. (a) Viral infection rapidly inhibits host RNA synthesis. Chloroplast, but not cytoplasmic, rRNAs are degraded beginning at about $30 \mathrm{~min}$ p.i. (b) PBCV-1 transcription is programmed, and the first transcripts appear within 5-10 min p.i. A few, but not all, early virus transcripts are synthesized in the absence of de novo protein synthesis. The synthesis of late transcripts requires translation of an early virus gene(s). (c) Early and late virus genes are interspersed throughout the PBCV-1 genome. (d) Gene full-length viral DNA probes often hybridize to mRNA transcripts that are $40-60 \%$ larger than the gene itself, suggesting that PBCV-1 contains overlapping genes, transcribes both strands of DNA, or posttranscriptionally modifies RNA, or that some transcripts are polycistronic. Transcription studies with individual PBCV-1 genes indicate that some genes produce the expected size mRNA as either an early or late gene, whereas other genes produce complex RNA patterns; these complex patterns occur even using ssDNA probes (e.g., the $\mathrm{K}^{+}$channel gene). (e) Transcription mapping of 7 PBCV-1 genes revealed that the virus has mRNAs with $5^{\prime}$ untranslated regions as small as 14 nucleotides and as large as 149 nucleotides. Transcripts also often extend beyond the translational stop codon $(60,61,171)$. To date, no early or late PBCV-1 promoters have been identified, although the 50 bases preceding most of the major ORFs are at least $70 \%$ AT. In addition, several genes including UDP-glucose dehydrogenase (95) and hyaluronan synthase (59) genes have -35 and -10 sites with spacing characteristic of Escherichia coli promoters (103).

PBCV-1 does not encode a recognizable RNA polymerase or RNA polymerase subunit. The lack of a virus-encoded RNA polymerase suggests that infecting viral DNAs are targeted to the cell nucleus and that a host RNA polymerase initiates viral transcription, possibly in conjunction with virus-packaged transcription factors. Consistent with this possibility, PBCV-1 encodes at least four transcrip- 
tion factor-like elements, TFIIB, TFIID, TFIIS, and VLTF-2. However, it is unknown if these proteins are active and if they are packaged in the virion.

PBCV-1 also encodes two enzymes involved in forming mRNA cap structure, an RNA triphosphatase (73) and an RNA guanylyltransferase (74). The size, amino acid sequence, and biochemical properties of the PBCV-1 capping enzymes resemble yeast-capping enzymes more than poxvirus and ASFV multifunctional RNA capping enzymes $(55,178)$. PBCV-1 also encodes an active RNase III that presumably processes either virus mRNAs or tRNAs (Y. Zhang, I. CalinJageman, J. R. Gurnon, B. Adams, A. W. Nicholson, \& J. L. Van Etten, manuscript in preparation). Finally, PBCV-1 encodes two proteins that contain sequence elements of superfamily II helicases. Superfamily II helicases are involved in transcription (196).

\section{Set Domain-Containing Protein}

PBCV-1 infection rapidly inhibits most, if not all, host transcription. Furthermore, at least some host transcription machinery is subverted to initiate virus transcription. The recent discovery that PBCV-1 encodes a small 120-amino acid protein (referred to as vSET) that methylates $\mathrm{Lys}^{27}$ in histone H3 (115) provides a possible mechanism for virus inhibition of host transcription. Proteins with $\sim 120$ amino acid SET domains often methylate histones [this process, including histone acetylation and phosphorylation, is often referred to as chromatin remodeling (e.g., 6)]. These methylating enzymes typically contain one or two SET domain(s) near their $C$ terminus preceded by several hundred amino acids. Presumably, the $\mathrm{N}$-terminal region confers histone specificity for SET-containing protein activity. Since the PBCV-1 enzyme consists solely of a SET domain, we predict that vSET methylates $\mathrm{Lys}^{27}$ residues in specific histone $\mathrm{H} 3 \mathrm{~s}$ and that such methylation results in the inhibition of most, if not all, host transcription. A recent report that the polycomb group of proteins inhibit expression of HOX genes in Drosophila by methylating $\mathrm{Lys}^{27}$ in histone $\mathrm{H} 3$ proteins (15) is consistent with histone H3 Lys ${ }^{27}$ methylation inhibiting transcription.

\section{PBCV-1 Protein Synthesis, Modification, And Degradation}

PBCV-1 infection rapidly inhibits host protein synthesis and some early virus proteins appear within 15 min p.i. PBCV-1 proteins are synthesized on cytoplasmic ribosomes and not organellar ribosomes since cycloheximide, but not chloramphenicol, inhibits viral replication (180). How the virus takes over the host translational machinery forcing it to translate virus mRNAs is not known.

The chlorella viruses are the first viruses known to encode a translation elongation factor (EF) enzyme (230). The putative protein from PBCV-1 has $\sim 45 \%$ amino acid identity to an EF-3 protein from fungi $(7,19)$. The fungal protein stimulates EF-1 $\alpha$-dependent binding of aminoacyl-tRNA to the A site of the ribosome. 
Like fungal EF-3 proteins, the PBCV-1 protein has an ABC transporter family signature and two ATP/GTP-binding site motifs.

PBCV-1 codon usage is biased to codons ending in A/U (63\%) over those ending in C/G (37\%) (171). This bias is expected because PBCV-1 DNA is $40 \% \mathrm{G}+$ $\mathrm{C}$, whereas host nuclear DNA is $67 \% \mathrm{G}+\mathrm{C}(212)$. Therefore, finding that PBCV-1 encodes 11 tRNA genes may not be surprising: 3 for Lys, 2 each for Asn and Leu, and 1 each for Ile, Tyr, Arg, and Val. None of the tRNAs has a CCA sequence encoded at the 3' end of the acceptor stem. Typically these 3 nucleotides are added separately to tRNAs. Some chlorella viruses encode as many as 16 tRNAs (22, 145). There is a strong correlation between the abundance of virus-encoded tRNAs and the virus gene codon use (145).

The virus-encoded tRNAs contain internal A and B boxes characteristic of RNA polymerase III promoter elements, suggesting the tRNAs might be transcribed individually by RNA polymerase III (145). However, the tRNA genes are transcribed as a large precursor RNA and processed via intermediates to mature tRNAs at both early and late stages of virus replication. Some, if not all, of the tRNAs are aminoacylated in vivo, suggesting they probably function in viral protein synthesis (145). Possibly, the virus-encoded EF-3 in combination with the virus-encoded tRNAs alter the host protein synthetic machinery to preferentially translate viral mRNAs.

Including glycosylation (see below), PBCV-1 encodes several enzymes involved in posttranslational modification. Like several large dsDNA viruses, PBCV- 1 encodes an ERV/ALR protein that functions as a protein thiol oxidoreductase (174). PBCV-1 also encodes a putative protein disulfide isomerase and a prolyl 4-hydroxylase that converts Pro-containing peptides into hydroxyl-Procontaining peptides (42). Finally, PBCV-1 encodes 7 putative Ser/Thr-protein kinases, 1 Tyrprotein kinase, and a Tyr phosphatase. With the exception of one of the Ser/Thr protein kinases (156), these protein kinase/phosphatase enzymes have not been studied. Three protein kinases are packaged in the related chlorella virus (CVK2) virion (231).

PBCV-1 encodes two putative proteins that interact with ubiquitin, a ubiquitin C-terminal hydrolase and a Skp1 protein. Skp1 proteins belong to the SCF-E3 ubiquitin ligase family that targets cell cycle and other regulatory factors for degradation (33). Finally, PBCV-1 encodes at least one putative serine proteinase.

\section{Protein Glycosylation}

Structural proteins of many viruses, such as herpesviruses, poxviruses, and paramyxoviruses, as well as the chlorella viruses, are glycosylated. Typically, viral proteins are glycosylated by host-encoded glycosyltransferases located in the endoplasmic reticulum (ER) and Golgi and then transported to a host membrane $(38,89,149)$. Nascent viruses acquire the glycoprotein(s) and only become infectious by budding through the membrane, usually as they are released from the cell. Consequently, the glycan portion of virus glycoproteins is host specific. 
However, glycosylation of PBCV-1 major capsid protein Vp54 differs from this paradigm. This conclusion originally arose from antibody studies. Polyclonal antiserum prepared against intact PBCV-1 virions inhibits virus plaque formation by agglutinating particles. Spontaneously derived, antiserum-resistant variants of PBCV-1 arise at a frequency of $\sim 10^{-6}$. These antiserum-resistant variants fall into five serologically distinct classes (219; M. V. Graves \& J. L. Van Etten, unpublished results). Polyclonal antisera prepared against members of each of these antigenic classes react exclusively with the Vp54 equivalent from the viruses in the class used in the immunization. The Vp54 equivalents from the variants migrate in a distinctive fashion on SDS-PAGE; the size of Vp54 in each variant is smaller than wild-type Vp54. Western blot analyses of Vp54 proteins, before and after removing the glycans, established that the antigenic variants reflect differences in the Vp54 glycans. In addition, the ratio of the 7 neutral sugars [glucose, fucose, galactose, mannose, xylose, rhamnose and arabinose (219)] associated with Vp54 from PBCV-1 and the variants change in a manner that correlates with antigenicity and Vp54 migration on SDS-PAGE.

Additional observations indicate that Vp54 glycosylation is unusual. (a) Unlike viruses that acquire their glycoprotein(s) by budding through a membrane, intact infectious PBCV-1 particles accumulate inside the host 30-40 min before virus release (206). (b) The nucleotide sequence of the vp54 gene in each of the variants is identical to PBCV-1 (219). (c) All of the variants are grown in the same host. (d) Antibodies to the virus do not react with host oligosaccharides. (e) Compounds that inhibit ER-Golgi localized N-linked glycosylation of proteins (tunicamycin) and ER to Golgi protein transport Brefeldin A $(39,107)$ neither affect PBCV-1 replication nor the $\mathrm{M}_{\mathrm{r}}$ of $\mathrm{Vp} 54$ at concentrations lethal to the host (155). (f) Variants from different classes can complement and recombine in dual infection experiments to produce wild-type progeny, indicating that the enzymes involved in glycosylation reside in different virus-encoded complementation groups (58). ( $g$ ) The Vp54 glycans lack N-acetylglucosamine (GlcNAc), a sugar commonly found in Asn-linked (Nlinked) and many O-linked glycoproteins produced via the cellular ER-Golgi pathway (164). (h) Unlike most glycoproteins that exhibit size microheterogeneity, Vp54 appears homogeneous on SDS-PAGEs; also mass spectrometry analysis only reveals one satellite peak. (i) The ability to easily crystallize Vp54 as a homotrimer provides additional evidence that the protein is homogeneous (140).

The Vp54 crystal structure also revealed the location of the glycans (140). Comparing the molecular mass of Vp54 with its predicted molecular weight from the amino acid sequence indicates that the protein contains $\sim 30$ sugar moieties, of which 20 could be ordered in the density map. Single sugars are attached to Ser ${ }^{57}$ and Ser ${ }^{387}$; six- and seven-branched chain sugar moieties are attached to Asn ${ }^{280}$ and $\mathrm{Asn}^{302}$, respectively, as well as three and two sugar residues at $\mathrm{Asn}^{399}$ and $\mathrm{Asn}^{406}$, respectively. As predicted from the antibody results, the four N-linked glycans face the external surface of the virus. GlcNAc fits the carbohydrate electron density at residues $\mathrm{Asn}^{280}, \mathrm{Asn}^{302}$, and $\mathrm{Asn}^{399}$. However, the inability to detect GlcNAc as one of the sugars associated with Vp54 suggests that another modified sugar might be in this position, possibly glucose with an O-linked acetate. 
The identification of the glycan-linked Asn residues in Vp54 provided additional evidence that glycosylation of Vp54 does not involve host glycosyltransferases. $\mathrm{Asn}^{302}, \mathrm{Asn}^{399}$, and $\mathrm{Asn}^{406}$ occur in the amino acid sequence motif (A/ G)NTXT, and Asn ${ }^{280}$ occurs in an ANIPG sequence. None of these Asn residues resides in a NX(T/S) sequence commonly recognized by endoplasmic reticulumand Golgi-located glycosyltransferases (164). This also explains why previous tests for N-glycosylation were negative (155). Taken together, the results suggest that PBCV-1 encodes the enzymes involved in constructing the glycans attached to $\mathrm{Vp} 54$.

Comparison of PBCV-1 ORFs to proteins in the databases identified seven possible glycosyltransferase-encoding genes, a64r, a111r, a114r, a222-226r, a328l, a473l, and $a 546 l$. None of these putative PBCV-1-encoded glycosyltransferases has an identifiable signal peptide that would target them to the ER. Furthermore, the cellular protein localization program PSORT predicts that all of these proteins, with the exception of A473L, are cytoplasmic. A473L is predicted to be in a membrane.

The $a 64 r$ gene encodes a 638 amino acid protein that has 4 motifs conserved in fringe-type glycosyltransferases. Analysis of 13 PBCV-1 antigenic variants revealed mutations in $a 64 r$ that correlated with a specific antigenic variation. Dual infection experiments with different antigenic variants indicated viruses that contained wild-type $a 64 r$ could complement and recombine with viruses that contained variant $a 64 r$ to form wild-type virus. Therefore, we concluded that $a 64 r$ encodes a glycosyltransferase involved in synthesizing the Vp54 glycan (58).

Collectively, the results indicate that glycosylation of the PBCV-1 major capsid protein differs from that of other viruses and that glycosylation is independent of the ER and Golgi apparatus. Could Vp54 glycosylation reflect an ancestral pathway that existed prior to ER and Golgi formation? Among many questions to be addressed, it will be important to determine if the Vp54 glycan precursor is attached to a lipid carrier such as undecaprenol-phosphate, which is the carrier for bacterial peptidoglycans and cell surface polysaccharides (158), or dolichol diphosphate, which is the carrier for eukaryotes (164).

\section{PBCV-1 Assembly and Release}

Like poxviruses, iridoviruses, and ASFV, PBCV-1 assembly occurs in localized regions in the cytoplasm, referred to as virus assembly centers. Therefore, one might expect the cytoskeleton to participate in either targeting the virus proteins to the virus assembly centers and/or assembling virus proteins into capsids. However, 13 cytoskeleton-disrupting agents, which inhibit either tubulin or actin functions, had little effect on formation of PBCV-1 virus assembly centers or PBCV-1 replication, even at concentrations higher than required to inhibit host chlorella growth (144). PBCV-1 empty capsids appear prior to filling with DNA (121).

The origin of the PBCV-1 internal membrane is unknown. Other large dsDNA viruses with internal membranes, including a brown algal virus that infects Hincksia hincksia (223) or ASFV (24), acquire their membrane by a pinching off of 
the ER, and PBCV-1 may use a similar mechanism. In support of this hypothesis, Songsri et al. (182) identified two urea-soluble proteins from virus CVK2 that contain an N-terminal $\sim 20$ amino acid hydrophobic sequence followed by a lysine. These sequences, which are absent in the native virion protein, resemble signal peptides that are cleaved in the lumen of the ER.

PBCV-1 also contains genes that encode putative lipid-metabolizing enzymes, glycerophosphoryl diesterase, 2-hydroxyacid dehydrogenase, and lysophospholipase. These enzymes could be involved in either synthesis or modification of the internal virus membrane. However, PBCV-1 deletion mutants, which lack the neighboring glycerophosphoryl diesterase and the 2-hydroxyacid dehydrogenase genes, still replicate in chlorella grown in the laboratory (94). The product of another PBCV-1 gene has a GNAT-N-acetyltransferase domain. This may be significant because three proteins associated with the PBCV-1 virion, including the major capsid protein, contain an amide-linked myristic acid (155). Typically, Nlinked myristic acids are attached to the N-terminal amino acid, usually a glycine, after removal of the terminal methionine (10). However, the myristic acid(s) attached to the PBCV-1 major capsid protein is linked to an internal amino acid, probably a lysine (155). The putative PBCV-1-encoded N-acetyltransferase could be responsible for this rare modification.

Timing the release of nascent virions from the host is critical and presumably involves at least some of the virus-encoded cell wall-digesting enzymes. Perhaps the chlorella viruses have something similar to holins, which time the release of dsDNA bacteriophages (218).

\section{Host Cell Surface Changes}

The discovery that PBCV-1 infection leads to host cells becoming covered with the linear polysaccharide hyaluronan, also called hyaluronic acid, was completely unexpected (59). Furthermore, PBCV-1 encodes the enzyme, hyaluronan synthase (HAS), responsible for its synthesis (30). Hyaluronan, a ubiquitous constituent of the extracellular matrix in vertebrates, is composed of $\sim 20,000$ alternating $\beta-1,4-$ glucuronic acid and $\beta-1,3-\mathrm{N}$-acetylglucosamine residues (28). Until the has gene was discovered in PBCV-1, hyaluronan was thought to occur only in vertebrates and a few pathogenic bacteria, where it forms an extracellular capsule, presumably to avoid the immune system $(28,29)$.

PBCV-1 also encodes two enzymes involved in the biosynthesis of hyaluronan precursors, glutamine:fructose-6-phosphate amidotransferase (GFAT) and UDPglucose dehydrogenase (UDP-GlcDH) (Figure 2A) (95). All three proteins are produced early in PBCV-1 infection and hyaluronan begins to accumulate as hyaluronan lyase-sensitive, hair-like fibers on the outside of the chlorella cell wall by 15-30 min p.i.; by $240 \mathrm{~min}$ p.i. the infected cells are covered with a dense fibrous hyaluronan network (59). The biosynthesis of a single hyaluronan chain requires a lot of energy; five ATP equivalents, two NAD cofactors, one acetyl CoA group and the two monosaccharide components are required to form each individual 
disaccharide unit (28). Therefore, hyaluronan presumably serves some essential purpose or provides a selective advantage to the virus.

The PBCV-1-encoded GFAT and UDP-GlcDH enzymes most closely resemble bacterial enzymes, whereas PBCV-1-encoded HAS resembles vertebrate enzymes. These observations suggest that the viruses may have acquired the gfat and $u d p$ glcdh genes separately from the has gene. One might expect these three genes to be clustered on the viral genome. However, this is not the case, whereas has and gfat genes are colinear and separated by only 99 nucleotides, they are located 240 $\mathrm{kb}$ from the $u d p$-glcdh gene.

We have considered three biological functions for the extracellular hyaluronan: (a) The polysaccharide prevents uptake of virus-infected chlorella by the paramecium. Presumably, such infected algae would lyse inside the paramecium and the released virions would be digested by the protozoan. This scenario would be detrimental to virus survival. (b) The viruses have another host that acquires virus by taking up the hyaluronan-covered algae. (c) Virus-infected cells aggregate, presumably due to the extracellular polysaccharide. This aggregation, which can trap uninfected cells, may aid the virus in finding its next host.

A complicating factor in understanding the biological importance of hyaluronan, however, is the discovery that not all chlorella viruses encode has and at least some virus-infected cells lack a surface polysaccharide (59). The story became even more bizarre with the recent discovery by Kawasaki et al. (87) that some chlorella viruses have a gene that encodes chitin synthase (chs) instead of a has gene. Chitin is a linear polysaccharide composed of $\beta$-1,4-linked $\mathrm{N}$-acetylglucosamine residues. Cells infected with viruses that have a chs gene accumulate chitin on their surface. A few viruses contain both a has gene and a chs gene and both polysaccharides appear on the surface of cells infected with these viruses (87).

The discovery of viral polysaccharide synthesis leads to many questions such as: (a) What is the function of these extracellular polysaccharides? (b) Why do infected cells expend huge amounts of energy for the processes when they are going to lyse in a few hours? (c) How were these genes acquired by the viruses?

\section{Additional PBCV-1 Genes}

\section{Fucose Synthesis}

As mentioned above, PBCV-1 encodes at least 7 putative glycosyltransferases and 3 enzymes involved in hyaluronan biosynthesis. In addition, PBCV-1 is the first virus known to encode enzymes involved in nucleotide sugar metabolism. The virus encodes two enzymes, GDP-D-mannose 4,6 dehydratase (GMD) and the bifunctional GDP-4-keto-6-deoxy-D-mannose epimerase/reductase (GMER), that comprise the highly conserved pathway that converts GDP-D-mannose to GDP-L-fucose (Figure 2B) (199). Experiments with recombinant GMD and GMER established that both virus proteins have properties comparable to human and bacterial enzymes. However, the PBCV-1 GMD is more stable than recombinant 
GMDs from other organisms. In addition to the dehydratase activity, the PBCV1 GMD also catalyzes NADPH-dependent reduction of the intermediate GDP-4keto-6-deoxy-D-mannose, forming GDP-D-rhamnose. As a consequence, in vitro reconstruction of the biosynthetic pathway using PBCV-1 GMD and GMER produces both GDP-L-fucose and GDP-D-rhamnose in the presence of NADPH (Figure $2 B$ ). Both fucose and rhamnose are present in the glycans attached to the virus major capsid protein Vp54. However, uninfected Chlorella NC64A cell walls contain rhamnose and trace amounts of fucose (119). Thus the uninfected chlorella synthesizes these two sugars. Presumably, the virus-encoded pathway could circumvent a limited supply of GDP-sugars by the host.

\section{Polyamine Biosynthetic Enzymes}

PBCV-1 is the first virus known to code for polyamine biosynthetic enzymes, including two separate pathways to synthesize putrescine (Figure 2C). Ornithine decarboxylase (ODC) catalyzes decarboxylation of ornithine to putrescine, which is the first and rate-limiting enzymatic step in the classical polyamine biosynthetic pathway $(25,27)$. Typically, ODC is subject to a variety of control mechanisms and the protein turns over rapidly in vivo in other organisms (25). Turnover is mediated by an antizyme protein that, at least in mammals, binds to a PEST sequence in ODC, and targets the enzyme for proteolysis by the $26 \mathrm{~S}$ proteasome $(25,45,66)$. The PBCV-1-encoded ODC is smaller (372 amino acids) than other ODCs. Despite its small size, the recombinant protein has good ODC activity (128). The virus enzyme lacks the two PEST sequences present in mammalian enzymes and thus may lack the regulation of more advanced ODCs. This suggestion is supported by phylogenetic analyses; the PBCV-1 ODC resides near the origin of the clade containing eukaryotic ODCs.

PBCV-1 ODC is more sensitive to the irreversible inhibitor difluoromethylarginine (DFMA) than to the specific ODC irreversible inhibitor difluoromethylornithine (DFMO) (128). This observation led to the discovery that the virus enzyme also has arginine decarboxylase activity (A. E. Pegg, unpublished results). The product of arginine decarboxylase is agmatine. Interestingly, PBCV-1 also encodes two enzymes, agmatine iminohydrolase and $\mathrm{N}$-carbamoylputrescine amidohydrolase, that convert agmatine to putrescine (Figure 2C) (138; M. Piotrowski, personal communication). PBCV-1 also encodes a functional $\mathrm{NAD}^{+}$-dependent enzyme (homospermidine synthase) that synthesizes the rare polyamine homospermidine from two molecules of putrescine (82).

The polyamines putrescine, spermidine, and spermine are common in cells and also are structural components of many viruses, where they help neutralize viral nucleic acids $(25,202)$. PBCV-1 virions, as well as uninfected and virus-infected Chlorella NC64A cells, contain putrescine, cadaverine, spermidine, and homospermidine. However, it is unlikely that these polyamines are important in neutralizing DNA because the number of polyamine molecules per virion could neutralize only $\sim 0.2 \%$ of DNA phosphate residues (82). Furthermore, the functional significance of polyamines in the PBCV-1 particle must be limited since 
they can be displaced by washing the particles in a polyamine-free buffer without affecting virus infectivity.

Thus it is unknown why PBCV-1 encodes so many polyamine biosynthetic enzymes. The PBCV-1 odc gene is expressed at both early and late times during virus infection (128), whereas the homospermidine synthase gene is only expressed late (82). Expression patterns of the other polyamine biosynthetic enzymes remain to be determined.

Finally, PBCV-1 encodes two other putative enzymes involved in amine metabolism, monoamine oxidase and histidine decarboxylase. Functions of these enzymes remain unclear.

\section{Ion Channel Proteins}

PBCV-1 was the first virus discovered to encode a functional $\mathrm{K}^{+}$channel protein. The 94-amino acid protein (called $\mathrm{Kcv}$ ) produces a $\mathrm{K}^{+}$-selective and slightly voltage-sensitive conductance in Xenopus oocytes (153) and mammalian HEK293 (129) and CHO cells (52). Kcv is the smallest protein known to form a functional $\mathrm{K}^{+}$selective channel and its transmembrane (TM1)-pore-TM2 structure corresponds to the "pore module" of $\mathrm{K}^{+}$channels. Because of its small size, $\mathrm{Kcv}$ is a model protein to study channel assembly and function (51). The $\mathrm{K}^{+}$channel inhibitors amantadine and $\mathrm{Ba}^{2+}$, but not $\mathrm{Cs}^{+}$, inhibit $\mathrm{K}^{+}$conductance in oocytes, as well as PBCV-1 plaque formation. Thus PBCV-1 Kcv activity is probably important in some aspect of virus replication.

One possible scenario is that the internal membrane of PBCV-1 contains KcV and that after digestion of the cell wall during infection, the virus membrane fuses with the host plasma membrane, triggering the release of virus DNA and associated proteins into the host. The fusion activates the Kcv channel and rapidly changes the host internal $\mathrm{K}^{+}$concentration, creating an altered membrane potential. This signal spreads rapidly to alter the entire host plasma membrane potential and prevents membrane fusion by a second virus, thus restricting infection by a second virus. This hypothesis is consistent with several observations: (a) Virus infection rapidly depolarizes the host plasma membrane (118). This depolarization displays the same sensitivity to inhibitors as Kcv conductance in oocytes. (b) Multiple virus particles can attach to and degrade the host cell wall without releasing their DNA (J. L. Van Etten, unpublished results). (c) The host exhibits an exclusion phenomenon (see section on DNA MTases and site-specific endonucleases) (20).

We have isolated genes encoding Kcv proteins from 40 additional chlorella viruses. In total, differences in 16 of the 94 amino acids have been observed, resulting in 6 new Kcv-like proteins. Amino acid differences occur in all the KcV functional domains. The 6 new Kcv-like proteins produced $\mathrm{K}^{+}$selective currents in Xenopus oocytes with new properties, e.g., current kinetics and inhibition by $\mathrm{Cs}^{+}$(M. Kang, S. Gazzarrini, M. Severino, D. DiFrancesco, G. Thiel, J. L. Van Etten, \& A. Moroni, manuscript in preparation). Single and multiple amino acid substitutions are being produced in Kcv to identify key amino acids that influence the $\mathrm{K}^{+}$currents. 
Often other proteins or compounds influence the assembly and/or function of $\mathrm{K}^{+}$channels, and PBCV-1 encodes several proteins that could mediate these processes: (a) Potassium ion channel activity is often modulated by phosphorylation and dephosphorylation (102) and PBCV-1 encodes eight protein kinases. In fact, a Ser/Thr protein kinase gene is adjacent to the $k c v$ gene in PBCV-1 as well as in many other chlorella viruses (M. Kang, M. V. Graves, M. Mehmel, A. Moroni, S. Gazzarrini, D. DiFrancesco, G. Thiel, J. R. Gurnon, \& J. L. Van Etten manuscript in preparation). (b) Polyamines inhibit biological activity of Kir type $\mathrm{K}^{+}$channels (43, 106, 109). PBCV-1 encodes at least four enzymes associated with polyamine biosynthesis (Figure 2C). (c) PBCV-1 encodes a putative histidine decarboxylase. Histamine, the product of histidine decarboxylase, is an important neurotransmitter of photoreceptors in insects and other arthropods (141). As a photoreceptor transmitter in insects, histamine acts on ligand-gated chloride ion channels. (d) PBCV1 encodes two adjacent but divergent ORFs (A162L and A163R) that resemble ligand-gated ion channel proteins (83). The A162L and A163R proteins have three properly spaced transmembrane domains that are typical of glutamate receptor ion channel proteins (34). Glutamate receptor channels mediate influx of cations $\left(\mathrm{K}^{+}, \mathrm{Na}^{+}\right.$, and $\left.\mathrm{Ca}^{2+}\right)$ across membranes $(34,123)$. However, the two PBCV-1 putative proteins lack recognizable glutamate binding sites. Expression of cRNAs from these two genes in oocytes failed to produce currents (83).

The connection, if any, between the putative PBCV-1-encoded protein kinases, polyamine biosynthetic enzymes, putative histidine decarboxylase, putative ligand-gated ion channel proteins, and Kcv is unknown. However, all of these components could be part of a regulated system for balancing ions and/or membrane potential within the host during virus replication.

\section{PBCV-1 Gene Families And Gene Duplications}

Eighty-four of the PBCV-1 ORFs resemble one or more other PBCV-1 ORFs forming 26 families. Thirteen families have two members, eight families have three members, three families have six members, and two families have eight members. One six-member family contains multiple ankyrin-like repeats (150). Five members in another family encode proteins that resemble the PBCV-1 major capsid protein Vp54. Like the Vp54 gene, the genes for four of these proteins are transcribed late in the infection cycle; expression of the fifth gene was not detected (M. V. Graves \& J. L. Van Etten, unpublished results). Although hybridization analysis indicates that these five additional capsid protein-like genes are not highly conserved among the chlorella viruses, the major capsid protein of a brown algal virus EsV-1 most closely resembles one of these other PBCV-1 major capsid-like proteins.

\section{Diversity of Chlorella Virus Genomes}

Not all PBCV-1 genes are required for virus replication in the laboratory. For example, four spontaneously derived, PBCV-1 mutants were isolated that contain $27-$ to $37-\mathrm{kb}$ deletions at the left end of the 330-kb genome (94). Two of these mu- 
tants, which probably resulted from recombination, have deletions beginning at nucleotide coordinates 4.9 or $16 \mathrm{~kb}$ and ending at $42 \mathrm{~kb}$. The other two deletion mutants, which probably arose from nonhomologous recombination, lack the entire left terminal $37-\mathrm{kb}$ of the PBCV-1 genome, including the 2.2-kb terminal inverted repeat region. The deleted left terminus is replaced by the transposition of an inverted 7.7- or 18.5-kb copy from the right end of the PBCV-1 genome. Taken together, $\sim 40 \mathrm{~kb}$ of single-copy DNA encoding 31 ORFs at the left end of the genome, or $12 \%$ of the PBCV-1 genome, is unnecessary for PBCV-1 replication in the laboratory. However, replication of the PBCV-1 deletion mutants is attenuated, i.e., their burst sizes are about half those of wild-type virus.

The deletion mutants also indicate that the size and sequence of the inverted terminal repeat regions are not conserved among chlorella viruses $(181,184,232)$. This nonconservation is somewhat surprising because one predicts that DNA termini are essential for either virus DNA replication and/or DNA packaging. These results also indicate that the virus DNA packaging machinery tolerates significant differences in genome size, e.g., the largest deletion in PBCV-1 creates a genome of $\sim 302 \mathrm{~kb}$, whereas another chlorella virus NY-2A has a genome of $\sim 380 \mathrm{~kb}$.

Large insertions also occur in the chlorella viruses. Comparison of PBCV-1 and CVK2 genomes revealed that an $\sim 15-\mathrm{kb}$ region in the PBCV-1 left terminal region is absent in the CVK2 genome. However, CVK2 contains a 22.2-kb insert in this region that contains five gene copies of a homolog of PBCV-1 glycoprotein Vp260; this 22.2-kb sequence is absent in the PBCV-1 genome $(23,146)$.

The sizes and locations of the deletions and transpositions found in the chlorella viruses resemble poxvirus (201) and ASFV (11) deletion mutants. Like PBCV-1, poxviruses and ASFV have inverted terminal repeats and covalently closed hairpin ends. Models proposed to explain the generation of deletions and deletion/transpositions in the poxvirus genomes $(175,201)$ may be relevant to the chlorella viruses.

Several years ago we grouped 37 viruses that infect Chlorella NC64A into 16 classes on the basis of plaque size, virion antiserum sensitivity, DNA restriction patterns, sensitivity of the DNAs to restriction endonucleases, and the amount and location of methylated bases in their DNAs (208). Hybridization of individual PBCV-1 genes with DNAs from these 37 chlorella viruses indicate that not every PBCV-1 gene is present in all NC64A viruses.

Several other observations reflect the diversity of chlorella virus genomes. (a) The virus NY-2A genome is about $50 \mathrm{~kb}$ larger than the PBCV-1 330-kb genome (165). (b) An extra ORF is often inserted between colinear genes (157). The insertion of extra genetic elements, termed "morons," between adjacent genes also occurs in related lambda phages (68). (c) PBCV-1 encodes 11 tRNA genes that are clustered with less than 33 intergenic nucleotides; other NC64A viruses encode clusters of up to 16 tRNA genes $(22,145)$. Clustering of tRNAs is common in bacteria and rare in eukaryotes. Some of the tRNA genes contain introns as large as $1 \mathrm{~kb}(145)$. (d) Sequence analyses of a gene $(p d g)$ encoding a UV-specific DNA repair enzyme from 42 NC64A viruses revealed that 15 contain a 98-nucleotide, spliceosomal-processed intron that is $100 \%$ conserved; four other viruses contain 
an identically positioned 81-nucleotide intron that is nearly $100 \%$ identical (189). In contrast, the nucleotides in the $p d g$ coding regions (exons) from the intron-containing viruses are $84 \%$ to $100 \%$ identical.

The $100 \%$ identity of the 98-nucleotide intron sequence in 15 viruses and the near $100 \%$ identity of an 81-nucleotide intron sequence in another 4 viruses implies that either the intron was acquired recently or there is strong selective pressure to maintain the DNA sequence of the intron once it is in the $p d g$ gene. However, the abilities of intron-containing and intron-lacking viruses to repair UV-damaged DNA in the dark were indistinguishable (189). These findings contradict the dogma that intron sequences are more variable than exon sequences (103).

(e) Yamada and his colleagues $(147,236)$ reported that $8 \%$ of the NC64A viruses isolated in Japan contain a self-splicing group I intron. The intron is inserted in the gene encoding either transcriptional elongation factor TFIIS ( $\sim 60 \%$ of the viruses) or an unidentified ORF encoding a $14.2-\mathrm{kDa}$ polypeptide ( $\sim 40 \%)$. Divergence of the self-splicing intron sequences is constrained by the exon regions, i.e., introns in the same gene have $>99 \%$ sequence identity, whereas introns in different genes have only 72-78\% identity. Phylogenetic analyses indicate these introns are distantly related to those found in rRNA genes in various microorganisms, including green algae, red algae, yeast, fungi, and protozoa, suggesting horizontal gene transfer between these distantly related organisms (93). Yamada et al. (236) suggested that the self-splicing intron might function as a mobile genetic element, e.g., transferring genes between algae and protists. In this context, it is noteworthy that 1 putative transposase and 12 putative group I intron homing endonuclease encoding genes are in PBCV-1.

To summarize, considerable variation occurs in the chlorella virus genomes, and the total number of genes in the chlorella virus gene pool exceeds that of a single isolate. The different sizes of the chlorella virus genomes as well as the large deletions and insertions suggest that dynamic and frequent rearrangements of virus genomes occur in natural environments. The fact that the left end of the chlorella virus genome is tolerant to deletions/insertions/rearrangements suggests that a recombinational "hotspot" in this region allows viruses to exchange genes among themselves and possibly with host(s). However, despite these differences, the location of 22 PBCV-1 genes, many of which are housekeeping genes, are nearly colinear in the 350-kb NC64A virus CVK2 (146), suggesting similar overall genome organization between the two chlorella virus isolates.

\section{Natural History of the Chlorella Viruses}

The natural history of the chlorella viruses is poorly understood, and major advances are needed in our understanding of their biology before we can fully appreciate their ecology and explain their evolutionary origin. The hosts for the chlorella NC64A and Pbi viruses, Chlorella NC64A and Chlorella Pbi, respectively, normally exist as hereditary endosymbionts in green isolates of the protozoan $P$. 
bursaria. However, the algae are resistant to virus infection when they are in the symbiotic relationship and are infected only when they are separated from the ciliate $(86,161)$. In the symbiotic unit, algae are enclosed individually in perialgal vacuoles surrounded by a host-derived membrane (160). The initial establishment of a successful symbiotic relationship and the long-term maintenance of symbiosis require that the algae resist digestion by the paramecium. Reassociation studies with different chlorella species and algae-free P. bursaria indicate that only symbiotic algae readily re-establish symbiosis with the paramecium (160). Other chlorella are digested. The chlorella provide an advantage to the paramecium in the symbiotic relationship because they fix $\mathrm{CO}^{2}$ and transfer sugars to the paramecium (159). The finding that paramecia protect chlorella from virus infection in the symbiotic relationship provides an advantage to the algae (161).

Chlorella NC64A and Chlorella Pbi were originally isolated from American and European strains of $P$. bursaria, respectively. Although the NC64A and Pbi viruses are morphologically, biologically, and biochemically similar, viruses that infect Chlorella NC64A neither infect nor attach to Chlorella Pbi, and Pbi viruses neither infect nor attach to Chlorella NC64A (161). The component sugars in the cell walls of Chlorella NC64A and Chlorella Pbi differ considerably (84). Because the viruses can distinguish the two chlorella isolates, we predicted that the host receptor for the viruses might also be the recognition factor for the paramecia. This hypothesis was incorrect, however, because both Chlorella NC64A and Chlorella Pbi established stable symbiotic relationships with both American and European isolates of P. bursaria (161).

NC64A viruses have been isolated from freshwater collected in the United States, South America, Australia, China, Japan, South Korea, Israel, and Italy. Pbi viruses initially were discovered in freshwater collected in Europe (162), and more recently in water collected in Australia, Canada, and the northern United States or at higher elevations in the western United States (M. Nelson, unpublished results). Therefore, the initial assumption that Pbi viruses were limited to Europe and the NC64A viruses were present only in the Americas and eastern Asia is incorrect. In fact, two water samples collected in Australia contained both NC64A and Pbi viruses (J. L Van Etten \& J. Rohozinski, unpublished results). The most important factors influencing the distribution of NC64A and Pbi viruses are probably latitude and altitude.

Typically, the chlorella virus titer in indigenous water is 1-100 plaque-forming units (PFU) per $\mathrm{ml}$, but titers as high as $1 \times 10^{5}$ PFU per $\mathrm{ml}$ have been obtained. The concentration of chlorella viruses fluctuates with the seasons; the highest titers are typically found in late spring $(214,233)$. However, a water sample was recently collected through the ice, with a titer of $>1000$ PFU per ml (M. Nelson, unpublished results).

It is unknown whether NC64A and Pbi viruses replicate exclusively in paramecium chlorella or whether they have another host(s). In fact, it is not even known if the symbiotic chlorella exist free of paramecia in natural environments. A single paramecium contains as many as 1000 algae, and if each chlorella produces 300 vi- 
rus particles, chlorella released from a single paramecium could produce 300,000 virus particles. This could account for the high virus titers occasionally observed. However, this number is artificially high, since not all chlorella would be infected in dilute solutions of virus and algae. For example, Wiggins \& Alexander (221) demonstrated that bacterial concentrations must exceed a threshold of about $10^{4}$ cells per $\mathrm{ml}$ to consistently support virus replication. It is also pertinent that anecdotal reports indicate green (symbiotic) paramecia are rare in nature.

The occasional high chlorella virus titers in indigenous waters are also surprising because the viruses are constantly exposed to solar radiation. Such radiation damages viral DNAs and inactivates viruses. For example, inactivation of bacteriophages and cyanophages occurs at rates of 0.4 to 0.8 per $\mathrm{h}$ in full sunlight $(191,192)$. The chlorella viruses have adapted to solar radiation by having access to two independent DNA repair systems (49). (a) PBCV-1 encodes a pyrimidine dimer-specific glycosylase (PDG) that initiates UV-induced thymidine dimer repair. This DNA repair system functions in both the light and the dark. (b) PBCV-1 also uses the host photolyase to repair UV-induced thymidine dimers (also called host cell reactivation) (49). The combined activities of these repair systems should enable PBCV-1 to effectively exploit their hosts under a range of environmental conditions and to withstand substantial solar radiation. We expected the PDG enzyme to be packaged in the virion and accompany the virus DNA into the host, where it could initiate DNA repair. However, attempts to detect the PDG protein in PBCV-1 virions were unsuccessful (49). The $p d g$ gene is expressed early after virus infection, however. PBCV-1 also encodes a putative $\mathrm{Cu} / \mathrm{Zn}$ superoxide dismutase that could help protect DNA from reactive oxygen species.

Once it was established that chlorella viruses were common in nature, we assumed that plaque-forming viruses of other eukaryotic algae might also be common. However, we were unable to detect plaque-forming viruses in freshwater on other Chlorella or Chlamydomonas species. Thus, lytic viruses may be limited to a few algae or they may exist as lysogens in nature and only infrequently become lytic.

Lysogeny is consistent with the observation by several investigators that virus-like particles (VLP) are observed infrequently in eukaryotic algae and that the particles are limited to certain stages of algal development (208). The apparent lack of infectivity of these VLPs is also consistent with lysogeny. The VLPs might either infect the host and resume a lysogenic relationship or be excluded by preexisting proviruses, as are bacteriophages. However, there is no evidence that chlorella viruses have a lysogenic phase.

Algae might also harbor viruses in a carrier-state relationship (also called pseudolysogeny), in which at any one time a small population of algae is infected by virus. This type of relationship occurs with some bacteriophages. We have observed a carrier-state relationship between PBCV-1 and Chlorella NC64A in the laboratory. That is, colonies of Chlorella NC64A occasionally grow in PBCV-1 plaques. Colonies picked from these plaques produce low concentrations of virus in liquid culture, even after repeated subculturing over several months, without 
lysing the culture. PBCV-1 DNA did not hybridize to DNA isolated from singlecolony isolates of these chlorella cells, which eliminates lysogeny. Furthermore, single-colony isolates from these cultures did not produce PBCV-1; however, about $25 \%$ of these isolates re-established the carrier-state relationship when reinoculated with PBCV-1. The remaining colonies were either sensitive or resistant to PBCV-1 (Y. Xia, M. P. Skrdla, \& J. L. Van Etten, unpublished results).

\section{Other Phycodnaviruses and Putative Phycodnaviruses}

Members and prospective members of the Phycodnavirus family are continually being discovered. They all have icosahedral morphology, an internal lipid membrane, and large dsDNA genomes of 160 to $560 \mathrm{~kb}(203,207)$. The viruses infect both freshwater and marine eukaryotic algae.

The largest virus genome sequenced to date, the 336-kb genome from virus EsV-1 that infects the marine filamentous brown alga Ectocarpus siliculosus, is a phycodnavirus (32). EsV-1 contains $~ 231$ putative protein-encoding genes, whereas the slightly smaller PBCV-1 genome contains 11 tRNA genes and $~ 373$ protein-encoding genes. Surprisingly, these two phycodnaviruses only have 33 common genes. Among the 33 common protein-encoding genes, 17 have no counterparts in the databases. Despite these genetic differences, phylogenetic analysis of their DNA polymerases indicate that all large algal viruses, including viruses that infect Micromonas pusilla, Emiliania huxleyi, and Chrysochromulina brevifilum, are more closely related to each other than to other dsDNA viruses $(17,21,100)$.

The low number of EsV-1 and PBCV-1 homologous genes can be attributed to several factors. First, four observations indicate that the phycodnaviruses have a long evolutionary history. (a) Phylogenic analyses of DNA polymerases place the phycodnavirus enzymes near the root of all eukaryotic $\delta$ DNA polymerases (216, 217). (b) Phylogenetic analyses of other PBCV-1-encoded proteins place the proteins near the root of their eukaryotic counterparts, e.g., the $\mathrm{K}^{+}$channel protein Kcv (153), ornithine decarboxylase (128), and GDP-D-mannose 4,6 dehydratase (G. Duncan \& J. L. Van Etten, unpublished results). (c) Despite the fact that EsV-1 and PBCV-1 encode a mixture of prokaryotic- and eukaryotic-like proteins, except for one repetitive region in the EsV-1 genome, the G+C contents (40\% for PBCV-1 and $52 \%$ for EsV-1) are quite uniform throughout their respective genomes. This pattern suggests that most of the genes have existed together in the viruses for a long time. (d) Some evolutionary biologists believe that the first eukaryotic cell resembled a unicellular green alga; consequently, if the algal viruses appeared and evolved with their hosts, their evolutionary history could date back more than 1.2 billion years $(65,169)$.

Second, even though the chlorella viruses and brown algal viruses have many common features, significant differences exist. (a) The chlorella viruses infect their unicellular host by digesting the cell wall at the point of attachment, similar to bac- 
teriophages. In contrast, EsV-1 and its relatives bind to the plasmalemma of the host's spores or gametes that lack a cell wall $(112,113)$. (b) The $320-$ to $380-k b$ chlorella virus genomes are linear, nonpermuted molecules with cross-linked hairpin ends. The 335-kb genome of EsV-1 has complementary ends that anneal to form a circular molecule $(32,97)$. (c) Most importantly, the brown algal viruses have a lysogenic phase in their life cycle and produce virus particles only in modified gametangium or sporangium initials (the reproductive cells) of their hosts $(31,132)$. In contrast, the chlorella viruses have no obvious lysogenic phase. A recent review compared the biological properties and the genes of PBCV-1 and EsV-1 (207).

Eight genetically distinct lytic viruses that infect the nanoflagellate Micromonas pusilla $(\mathrm{MpV})$ were isolated from five locations in the Pacific and Atlantic Oceans and the Gulf of Mexico (26). The proportion of identical nucleotides for all pairwise combinations of the dnapol gene among the eight $\mathrm{MpV}$ viruses ranged from $78 \%$ to $99 \%$, indicating substantial differences in a portion of the gene that is typically highly conserved (21).

Other algal viruses have been studied primarily because of their importance in regulating phytoplankton communities in marine environments $(9,12,190,224)$. Viruses are reportedly associated with disappearance of "brown tides" caused by Aureococcus anophagefferens (179) and "red tides" caused by Heterosigma akashiwo (135-137). Likewise, Bratbak et al. (13) reported that virus lysis accounted for $>25 \%$ of the mortality in Emiliania huxleyi blooms.

Bratbak and colleagues have isolated lytic viruses specific for Emiliania huxleyi (EhV) (17), Phaeocystis pochetii (PpV) (80), Chrysochromulina ericina (CeV-01B) (168), and Pyramimonas orientalis (PoV-01B) (168) that have genomes of 412, 485, 510 , and $560 \mathrm{~kb}$, respectively. If the gene densities of these viruses are similar to PBCV-1, they have about 466, 549, 578, and 634 protein-encoding genes, respectively. These values are as high or higher than the 470 genes encoded by the smallest mycoplasma (48). Except for EhV, these viruses, which can be difficult to grow in culture, are largely uncharacterized. However, the sequence of the 412$\mathrm{kb}$ EhV genome is nearly complete (W. Wilson, personal communication), and it will be fascinating to compare the genes encoded by this virus with those encoded by PBCV-1 and EsV.

\section{Final Comments}

Research on the chlorella viruses is in its infancy and without doubt many more surprises await discovery. However, even with our limited knowledge many excellent scientific and economic reasons justify increased research on the chlorella viruses as well as other algal viruses. (a) The chlorella viruses encode 373 or more genes. Some of the other algal viruses probably have even more genes and the genomic complexity of these viruses approaches that of mycoplasma. (b) Algal viruses play a dynamic, albeit largely unknown, role in regulating phytoplankton communities in aqueous environments, such as the termination of algal blooms. 
(c) The chlorella viruses, as well as other algal viruses, are sources of new and unexpected genes. The genes not only encode commercially important enzymes such as DNA restriction endonucleases, but many viral enzymes are the smallest in their class. Consequently, these proteins serve as models for mechanistic and structural studies. (d) The viruses are a novel source of genes and genetic elements that can be used to engineer other organisms. Examples include: 1. PBCV-1 promoter elements function well in higher plants, both in monocots and dicots (126). The promoter elements also work well in bacteria (127; Y. Xia \& J. L. Van Etten, unpublished results) and mammalian cells (M. V. Graves, unpublished results). 2. Expression of the PBCV-1 gene encoding the pyrimidine dimer-specific glycosylase enzyme in baculovirus increased its resistance to UV inactivation (151). One disadvantage to using baculoviruses as biological control agents is their susceptibility to inactivation by UV-light. (e) The chlorella viruses contain a mosaic of prokaryotic and eukaryotic genes and may be related to the last common ancestor of these two kingdoms. In fact, accumulating evidence indicates the algal viruses and their genes have a long evolutionary history. Consequently, studies on these viruses could reveal interesting aspects about the evolution of genes and genomes. We encourage more investigators to study these viruses.

\section{Acknowledgments}

I thank Les Lane, Michael Graves, Dave Dunigan, Mike Nelson James Gurnon, Lisa Fitzgerald, and Takashi Yamada for critically reading the manuscript. I acknowledge the many contributions to the chlorella virus field by my long-time research collaborator Russ Meints (now retired). Finally, I thank the many students, postdocs, technicians, and research collaborators who have worked on various aspects of the chlorella viruses over the years. These interactions have been personally gratifying as well as scientifically exciting. Research from my lab has been supported in part by Public Health Service Grant GM32441 from the National Institute of General Medical Sciences. The three-dimensional reconstructions of PBCV-1 (Figure 1) were kindly provided by Xiaodong Yan and Tim Baker of Purdue University.

\section{Literature Cited}

1. Afonso CL, Tulman ER, Lu Z, Oma E, Kutish GF, Rock DL. 1999. The genome of Melanoplus sanguinipes entomopoxvirus. J. Virol. 73:533-52

2. Antequera F, Bird A. 1993. CpG islands. In DNA Methylation, Molecular Biology and Biological Significance, ed. PJ Jost, PH Saluz, pp. 169-85. Basel: Birkhauser

3. Arezi B, Kuchta RD. 2000. Eukaryotic DNA primase. Trends Biochem. Sci. 25:572-76

4. Ayres MD, Howard SC, Kuzio J, Lopez- Ferber M, Possee RD. 1994. The complete DNA sequence of Autographa californica nuclear polyhedrosis virus. Virology 202:586-605

5. Bamford DH, Caldentey J, Bamford JK. 1995. Bacteriophage PRD1: a broad host range dsDNA Tectivirus with an internal membrane. Adv. Virus Res. 45:281-319

6. Bannister AJ, Schneider R, Kouzarides T. 2002. Histone methylation: dynamic or static? Cell 109:801-6 
7. Belfield GP, Tuite MF. 1993. Translation elongation factor 3: a fungusspecific translation factor? Mol. Microbiol. 9:411-18

8. BelfortM,Roberts RJ. 1997. Homing endonucleases: keeping the house in order. Nucleic Acids Res. 25:3379-88

9. Bergh O, Borsheim KY, Bratbak G, Heldal M. 1989. High abundance of viruses found in aquatic environments. Nature 340:467-68

10. Bhatnagar RS, Futterer K, Waksman G, Gordon JI. 1999. The structure of myristoylCoA: protein N-myristoyltransferase. Biochem. Biophys. Acta 1441: 162-72

11. Blasco R, Aguero M, Almendral JM, Vinuela E. 1989. Variable and constant regions in African swine fever virus DNA. Virology 168:330-38

12. Borsheim KY, Bratbak G, Hedal M. 1990. Enumeration and biomass estimation of planktonic bacteria and viruses by transmission electron microscopy. Appl. Environ. Microbiol. 56:352-56

13. Bratbak G, Thingstad TF, Heldal M. 1993. Viral mortality of the marine alga Emiliania huxleyi Haptophyceae and termination of algal blooms. Mar. Ecol. Prog. Ser. 93:39-48

14. Burbank DE, Shields SL, Schuster AM, Van Etten JL. 1990. 5-Azacytidine resistant mutants of chlorella virus IL-3A. Virology 176:311-15

15. Cao R, Wang L, Wang H, Xia L, Erdjument-Bromage H, et al. 2002. Role of histone H3 Lysine 27, methylation in polycomb-group silencing. Science 298: 1039-43

16. Caspar DLD, Klug A. 1962. Physical principles in the construction of regular viruses. Cold Spring Harbor Symp. Quant. Biol. 27:1-24

17. Castberg T, Thyrhaug R, Larsen A, Sandaa R-A, Heldal M, et al. 2002. Isolation and characterization of a virus that infects Emiliania huxleyi (Haptophyta). J. Phycol. 38:767-74

18. Ceska TA, Sayers JR. 1998. Structurespecific DNA cleavage by 5 ' nucleases. Trends. Biochem. Sci. 23:331-36

19. Chakraburtty K. 2001. Translational regulation by ABC systems. Res. Microbiol. 152:391-99

20. Chase TE, Nelson JA, Burbank DE, Van Etten JL. 1989. Mutual exclusion occurs in a chlorella-like green alga inoculated with two viruses. J. Gen. Virol. 70:1829- 36

21. Chen F, Suttle CA. 1996. Evolutionary relationships among large doublestranded DNA viruses that infect microalgae and other organisms as inferred from DNA polymerase genes. Virology 219:170-78

22. Cho HH, Park HH, Kim JO, Choi TJ. 2002. Isolation and characterization of chlorella viruses from freshwater sources in Korea. Mol. Cell 14:168-76

23. Chuchird N, Nishida K, Kawasaki T, Fujie M, Usami S, Yamada T. 2002. A variable region on the chlorovirus CVK2 genome contains five copies of the gene for Vp260, a viral-surface glycoprotein. Virology 295:289-98

24. Cobbold C, Whittle JT, Wileman T. 1996. Involvement of the endoplasmic reticulum in the assembly and envelopment of African swine fever virus. J. Virol. 70:8382-90

25. Cohen SS. 1998. A Guide to the Polyamines. New York: Oxford Univ. Press. 595 pp.

26. Cottrell MT, Suttle CA. 1991. Wide spread occurrence and clonal variation in viruses which cause lysis of a cosmopolitan, eukaryotic marine phytoplankter, Micromonas pusilla. Mar. Ecol. Prog. Ser. 78:1-9

27. Davis RH, Morris DR, Coffino P. 1992. Sequestered end products and enzyme regulation: the case of ornithine decarboxylase. Microbiol. Rev. 56:280- 90 
28. DeAngelis PL. 1999. Hyaluronan synthases: fascinating glycosyltransferases from vertebrates, bacterial pathogens, and algal viruses. Cell Mol. Life Sci. 56: 670-82

29. DeAngelis PL. 2002. Evolution of glycosaminoglycans and their glycosyltransferases: Implications for the extracellular matrices of animals and the capsules of pathogenic bacteria. Anat. Rec. 268:317-26

30. DeAngelis PL, JingW, GravesMV, Burbank DE, Van Etten JL. 1997. Hyaluronan synthase of chlorella virus PBCV-1. Science 278:1800-3

31. Delaroque N, Maier I, Knippers R, Müller DG. 1999. Persistent virus integration into the genome of its algal host, Ectocarpus siliculosus (Phaeophyceae). J. Gen. Virol. 80:1367-70

32. Delaroque N,Müller DG, Bothe G, Pohl T, Knippers R, Boland W. 2001. The complete DNA sequence of the Ectocarpus siliculosus virus genome. Virology 287:112-32

33. Deshaies RJ. 1999. SCF and Cullin/ RING H2-based ubiquitin ligases. Annu. Rev. Cell. Dev. Biol. 15:435-67

34. Dingledine R, Borges K, Bowie D, Traynelis SF. 1999. The glutamate receptor ion channels. Pharmacol. Rev. 51:7- 61

35. Dodds JA. 1979.Viruses of marine algae. Experientia 35:440-42

36. Doermann AH. 1983. Introduction to the early years of bacteriophage T4. In Bacteriophage T4, ed. CK Mathews, EM Kutter, G Mosig, PB Berget, pp 1-7. Washington, DC: Am. Soc. Microbiol.

37. Dolan A, Jamieson FE, Cunningham C, Barnett BC, McGeoch DJ. 1998. The genome sequence of herpes simplex virus type 2. J. Virol. 72:2010-21

38. Doms RW, Lamb RA, Rose JK, Helenius A. 1993. Folding and assembly of viral membrane proteins. Virology 193:545- 62

39. Doms RW, Russ G, Yewdell JW. 1989. Brefeldin A redistributes resident and itinerant Golgi proteins to the endoplasmic reticulum. J. Cell Biol. 109:61-72

40. Dynes JL, Firtel RA. 1989. Molecular complementation of a genetic marker in Dictyostelium using a genomic DNA library. Proc. Natl. Acad. Sci. USA 86: 7966-70

41. Ellison V, Stillman B. 2001. Opening of the clamp: an intimate view of an ATPdriven biological machine. Cell 106: 655-60

42. Eriksson M, Myllyharju J, Tu H, Hellman M, Kivirikko KI. 1999. Evidence for 4-hydroxyproline in viral proteins: characterization of a viral prolyl 4- hydroxylase and its peptide substrates. J. Biol. Chem. 274:22131-34

43. Ficker E,TaglialatelaM,WibleBA, Henley CM, Brown AM. 1994. Spermine and spermidine as gating molecules for inward rectifier $\mathrm{K}^{+}$channels. Science 266:1068-72

43a. Fields BN, Knipe DM, Howley PM, Chanock RM, Melnick JL, et al. eds. 1996. Fields Virology. Philadephia: Lippincott-Raven. 3rd ed.

44. Fitzgerald MC, Skowron P,Van Etten JL, Smith LM, Mead DA. 1992. Rapid shotgun cloning utilizing the two base recognition endonuclease CviJI. Nucleic Acids Res. 20:3753-62

45. Fong WF, Heller JS, Canellakis ES. 1976. The appearance of an ornithine decarboxylase inhibitory protein upon the addition of putrescine to cell cultures. Biochim. Biophys. Acta. 428:456-65

46. Fortune JM, Dickey JS, Lavrukhin OV, Van Etten JL, Lloyd RS, Osheroff N. 2002. Sitespecific DNA cleavage by chlorella virus topoisomerase II. Biochemistry 41:11761-69

47. Fortune JM, Lavrukhin OV, Gurnon JR, Van Etten JL, Lloyd RS, Osheroff N. 2001. Topoisomerase II from chlorella virus PBCV-1 has an exceptionally high DNA cleavage activity. J. Biol. Chem. 276:24401-8 
48. Fraser CM, Gocayne JD, White O, Adams MD, Clayton RA, et al. 1995. The minimal gene complement of Mycoplasma genitalium. Science 270:397- 403

49. Furuta M, Schrader JO, Schrader HS, Kokjohn TA, Nyaga S, et al. 1997. Chlorella virus PBCV-1 encodes a homolog of the bacteriophage T4 UV DNA repair gene denV. Appl. Environ. Microbiol. 63:1551-56

50. Gardiner-Garden M, Frommer M. 1987. CpG islands in vertebrate genomes. J. Mol. Biol. 196:261-82

51. Gazzarrini S, Van Etten JL, DiFrancesco D, Thiel G, Moroni A. 2002. Voltagedependence of virus-encoded miniature $\mathrm{K}^{+}$channel Kcv. J. Membr. Biol. 187:15- 25

52. Gazzarrini S, Severino M, Morandi M, Lombardi M, DiFrancesco D, et al. 2003. The viral $\mathrm{K}^{+}$channel Kcv: Structural and functional features. FEBS Lett. In press

53. [deleted]

54. Girton L,Van Etten JL. 1987. Restriction site map of the chlorella virus PBCV-1 genome. Plant Mol. Biol. 9:247-57

55. Gong C, Shuman S. 2002. Chlorella virus RNA triphosphatase: mutational analysis and mechanism of inhibition by tripolyphosphate. J. Biol. Chem. 277: 15317-24

56. GoodayGW, Humphreys AM, McIntosh WH. 1986. Role of chitinases in fungal growth. See Ref. 133a, pp. 83-91

57. Grabherr R, Strasser P, Van Etten JL. 1992. The DNA polymerase gene from chlorella viruses PBCV-1 and NY-2A contains an intron with nuclear splicing sequences. Virology 188:721-31

58. Graves MV, Bernadt CT, Cerny R, Van Etten JL. 2001. Molecular and genetic evidence for a virus-encoded glycosyltransferase involved in protein glycosylation. Virology 285:332-45

59. Graves MV, Burbank DE, Roth R, Heuser J, DeAngelis PL, Van Etten JL. 1999. Hyaluronan synthesis in virus PBCV-1 infected chlorella-like green algae. Virology 257:15-23

60. Graves MV, Meints RH. 1992. Characterization of the gene encoding the most abundant in vitro translation product from virus-infected chlorella-like algae. Gene 113:149-55

61. Graves MV, Meints RH. 1992. Characterization of the major capsid protein and cloning of its gene from algal virus PBCV-1. Virology 188:198-207

62. Hakansson K, Doherty AJ, Shuman S, Wigley DB. 1997. X-ray crystallography reveals a large conformational change during guanyl transfer by mRNA capping enzymes. Cell 89:543-53

63. Hakansson K, Wigley DB. 1998. Structure of a complex between a cap analogue and mRNA guanylyl transferase demonstrates the structural chemistry of RNA capping. Proc. Natl. Acad. Sci. USA 95:1505-10

64. HayesW. 1968. The Genetics of Bacteria and Their Viruses. Oxford, UK: Blackwell Sci. 925 pp. 2nd ed.

65. Heckman DS, Geiser DM, Eidell BR, Stauffer RL, Kardos NL, Hedges SB. 2001. Molecular evidence for the early colonization of land by fungi and plants. Science 293:1129-33

66. Heller JS, Fong WF, Canellakis ES. 1976. Induction of a protein inhibitor to ornithine decarboxylase by the end products of its reaction. Proc. Natl. Acad. Sci. USA 73:1858-62

67. Hellmann V, Kessler E. 1974. Physiologische und biochemische Beitrage zur Taxonomie der Gattung Chlorella. VIII. Die Basenzusammensetzung der DNS. Arch. Microbiol. 95:311-18

68. Hendrix RW, Lawrence JG, Hatfull GF, Casjens S. 2000. The origins and ongoing evolution of viruses. Trends Microbiol. 8:504-8 
69. Herth W, Mulisch M, Zugenmaier P. 1986. Comparison of chitin fibril structure and assembly in three unicellular organisms. See Ref. 133a, pp. 107-20

70. Higashiyama T, Yamada T. 1991. Electrophoretic karyotyping and chromosomal gene mapping of chlorella. Nucleic Acids Res. 19:6191-95

71. Hiramatsu S, Fujie M, Usami S, Sakai K, Yamada T. 2000. Two catalytic domains of chlorella virus CVK2 chitinase. J. Biosci. Bioeng. 89:252-57

72. Hiramatsu S, Ishihara M, Fujie M, Usami S, Yamada T. 1999. Expression of a chitinase gene and lysis of the host cell wall during chlorella virus CVK2 infection. Virology 260:308-15

73. Ho CK, Gong C, Shuman S. 2001. RNA triphosphatase component of the mRNA capping apparatus of Paramecium bursaria Chlorella virus 1. J. Virol. 75:1744-50

74. Ho CK, Van Etten JL, Shuman S. 1996. Expression and characterization of an RNA capping enzyme encoded by chlorella virus PBCV-1. J. Virol. 70: 6658-64

75. Ho CK, Van Etten JL, Shuman S. 1997. Characterization of an ATP-dependent DNA ligase encoded by chlorella virus PBCV-1. J. Virol. 71:1931-37

76. Hubscher U, Nasheuer HP, Syvaoja JE. 2000. Eukaryotic DNA polymerases, a growing family. Trends Biochem. Sci. 25:143-47

77. Hutson MS, Holzwarth G, DukeT,Viovy JL. 1995. Two-dimensional motion of DNA bands during $120 \pm$ pulsed-field gel electrophoresis. I. Effect of molecular weight. Biopolymers 35:297-306

78. Itaya M. 1995. An estimation of minimal genome size required for life. FEBS Lett 362:257-60

79. Iyer LM, Aravind L, Koonin EV. 2001. Common origin of four diverse families of large eukaryoticDNAviruses. J. Virol. 75:11720-34

80. Jacobsen A, Bratbak G, Heldal M. 1996. Isolation and characterization of a virus infecting Phaeocystis pouchetii Prymnesiophyceae. J. Phycol. 32:923-27

81. Jaruga P, Jabil R, McCullough AK, Rodriguez H, Dizdaroglu M, Lloyd RS. 2002. Chlorella virus pyrimidine dimer glycosylase excises ultraviolet radiation and hydroxyl radical-induced products 4,6-diamino-5-formamidopyrimidine and 2,6-diamino-4-hydroxy-5- formamidopyrimidine from DNA. Photochem. Photobiol. 75:85-91

82. Kaiser A, Vollmert M, Tholl D, Graves MV, XingW, et al. 1999. Chlorella virus PBCV-1 encodes a functional homospermidine synthase. Virology 263:254-62

83. Kang M, Moroni A, Gazzarrini S, Van Etten JL. 2003. Are algal viruses a rich source of ion channel genes? FEBS Lett. In press

84. Kapaun E, Loos E, ReisserW. 1992. Cell wall composition of virus-sensitive symbiotic chlorella species. Phytochemistry 31:3103-4

85. Kapaun E, ReisserW1995. A chitin-like glycan in the cell wall of a Chlorella sp. Chlorococcales, Chlorophyceae. Planta 197:577-82

86. Kawakami H, Kawakami N. 1978. Behavior of a virus in a symbiotic system. Paramecium bursaria-zoochlorella. J. Protozool. 25:217-25

87. Kawasaki T, Tanaka M, Fujie M, Usami S, Sakai K, Yamada T. 2002. Chitin synthesis in chlorovirus CVK2-infected chlorella cells. Virology 302:123-31

88. Kelman Z, Hurwitz J. 2000. A unique organization of the protein subunits of the DNA polymerase clamp loader in the archaeon Methanobacterium thermoatuotrophicum delta H. J. Biol. Chem. 275:7327-36

89. Knipe DM. 1996. Virus-host cell interactions. See Ref. 43a, pp. 273-99

90. Kowalski JC, Belfort M, Stapleton MA, Holpert M, Dansereau JT, et al. 1999. Configura- 
tion of the catalytic GIYYIG domain of intron endonuclease ITevI: coincidence of computational and molecular findings. Nucleic Acids Res. 27:2115-25

91. Kumar S, Cheng X, Klimasauskas S, Mi S, Posfai J, et al. 1994. The DNA (cytosine-5) methyltransferases. Nucleic Acids Res. 22:1-10

92. Kutish GF, Li Y, Lu Z, Furuta M, Rock DL, Van Etten JL. 1996. Analysis of $76 \mathrm{~kb}$ of the chlorella virus PBCV-1 330- kb genome: map positions 182 to 258. Virology 223:303-17

93. Lambowitz AM, Belfort M. 1993. Introns as mobile genetic elements. Annu. Rev. Biochem. 62:587-662

94. Landstein D, Burbank DE, Nietfeldt JW, Van Etten JL. 1995. Large deletions in antigenic variants of the chlorella virus PBCV-1. Virology 214:413-20

95. Landstein D, Graves MV, Burbank DE, DeAngelis P, Van Etten JL. 1998. Chlorella virus $\mathrm{PBCV}-1$ encodes functional glutamine: fructose-6-phosphate amidotransferase and UDP-glucose dehydrogenase enzymes. Virology 250:388-96

96. Langridge WHR, Roberts DW. 1977. Molecular weight of DNA from four entomopoxviruses determined by electron microscopy. J. Virol. 21:301-8

97. Lanka STJ, Klein M, Ramsperger U, Müller DG, Knippers R. 1993. Genome structure of a virus infecting the marine brown alga Ectocarpus siliculosus. Virology 193:802-11

98. Larsen F, Gundersen G, Lopez R, Prydz H. 1992. CpG islands as gene markers in the human genome. Genomics 13:1095- 107

99. Lavrukhin OV, Fortune JM, Wood TG, Burbank DE, Van Etten JL, et al. 2000. Topoisomerase II from chlorella virus PBCV-1. Characterization of the smallest known type II topoisomerase. J. Biol. Chem. 275:6915-21

100. LeeAM,Ivey RG, Meints RH. 1998. The DNA polymerase gene of a brown algal virus: structure and phylogeny. J. Phycol. 34:608-15

101. Lemke PA. 1976. Viruses of eucaryotic microorganisms. Annu. Rev. Microbiol. 30:105-45

102. Levitan IB. 1994. Modulation of ion channels by protein phosphorylation and dephosphorylation. Annu. Rev. Physiol. 56:193-212

103. Lewin B. 1997. Genes VI. Oxford: Oxford Univ. Press. 1260 pp.

104. Li Y, Lu Z, Burbank DE, Kutish GF, Rock DL, Van Etten JL. 1995. Analysis of $43 \mathrm{~kb}$ of the chlorella virus PBCV-1 $330 \mathrm{~kb}$ genome: map position 45 to 88. Virology 212:134-50

105. Li Y, Lu Z, Sun L, Ropp S, Kutish GF, et al. 1997. Analysis of $74 \mathrm{~kb}$ of DNA located at the right end of the 330-kb chlorella virus PBCV-1 genome. Virology 237:360-77

106. Lin TI, Heider H, Schroeder C. 1997. Different modes of inhibition by a damantane amine derivatives and natural polyamines of the functionally reconstituted influenza virus M2 proton channel protein. J. Gen. Virol. 78:767-74

107. Lippincott-Schwartz J, Yuan LC, Bonifacino JS, Klausner RD. 1989. Rapid redistribution of Golgi proteins into the ER in cells treated with brefeldin A: evidence for membrane cycling from Golgi to ER. Cell 56:801-13

108. Loos E, Meindl D. 1982. Composition of the cell wall of Chlorella fusca. Planta 156:270-73

109. Lopatin AN, Makhina EN, Nichols CG. 1994. Potassium channel block by cytoplasmic polyamines as the mechanism of intrinsic rectification. Nature 372:366- 69

110. Lu Z, Li Y, Que Q, Kutish GF, Rock DL, Van Etten JL. 1996. Analysis of $94 \mathrm{~kb}$ of the chlorella virus PBCV-1 330-kb genome: map positions 88 to 182. Virology 216:102-23

111. Lu Z, Li Y, Zhang Y, Kutish GF, Rock DL, Van Etten JL. 1995. Analysis of $45 \mathrm{~kb}$ of DNA located at the left end of the chlorella virus PBCV-1 genome. Virology 206:339-52 
112. Maier I, Müller DG. 1998. Virus binding to brown algal spores and gametes visualized by DAPI fluorescence microscopy. Phycologia 37:60-63

113. Maier I, Muller DG, Katsaros C. 2002. Entry of the DNA virus, Ectocarpus fasciculatus virus type 1 (Phycodnaviridae), into host cell cytosol and nucleus. Phycol. Res. 50:227-31

114. Malone TE, Blumenthal RM, Cheng X. 1995. Structure-guided analysis reveals nine sequence motifs conserved among DNA amino-methyltransferases, and suggests a catalytic mechanism for these enzymes. J. Mol. Biol. 253:618- 32

115. Manzur KL, Farooq A, Zeng L, Plotnikova O, Koch AW, et al. 2003. A dimeric viral SET domain methyltransferase specific to Lys27 of histone H3. Nat. Struct. Biol. 10:187-96

116. McCluskey K, Graves MV, Mills D, Meints RH. 1992. Replication of chlorella virus PBCV-1 and host karyotype determination studies with pulsed-field gel electrophoresis. J. Phycol. 28:846-50

117. McCullough AK, Romberg MT, Nyaga S, Wei Y, Wood TG, et al. 1998. Characterization of a novel cis-syn and transsyn- II pyrimidine dimer glycosylase/AP lyase from a eukaryotic algal virus, Paramecium bursaria chlorella virus-1. J. Biol. Chem. 273:13136-42

118. Mehmel M, Rothermel M, MeckelT,Van Etten JL, Moroni A, Thiel G. 2003. Possible function for virus encoded $\mathrm{K}^{+}$channel $\mathrm{Kcv}$ in the replication of chlorella virus PBCV-1 FEBS Lett. In press

119. Meints RH, Burbank DE, Van Etten JL, Lamport DTA. 1988. Properties of the chlorella receptor for the virus PBCV-1. Virology 164:15-21

120. Meints RH, Lee K, Burbank DE, Van Etten JL. 1984. Infection of a chlorella-like alga with the virus, PBCV-1: ultrastructural studies. Virology 138:341-46

121. Meints RH, Lee K, Van Etten JL. 1986. Assembly site of the virus PBCV-1 in a chlorella-like green alga: ultrastructural studies. Virology 154:240-45

122. Meints RH,Van Etten JL,Kuczmarski D, Lee K, Ang B. 1981. Viral infection of the symbiotic chlorella-like alga present in Hydra viridis. Virology 113:698-703

123. Miller C. 2000. Ion channel surprises: Prokaryotes do it again. Neuron 25:7-9

124. Miller ES, Kutter E, Mosig G, Arisaka F,Kunisawa T, RugerW. 2003. Bacteriophage T4 Genome. Microbiol. Mol. Biol. Rev. 67:86-156

125. Mindich L, Bamford D. 1988. Lipidcontaining bacteriophages. The Bacteriophages, ed. R. Calendar, 2:475-520. New York: Plenum

126. Mitra A, Higgins DW. 1994. The chlorella virus adenine methyltransferase gene promoter is a strong promoter in plants. Plant Mol. Biol. 26:85-93

127. Mitra A, Higgins DW, Rohe NJ. 1994. A chlorella virus gene promoter functions as a strong promoter both in plants and bacteria. Biochem. Biophys. Res. Commun. 204:187-94

128. Morehead TA, Gurnon JR, Adams B, Nickerson KW, Fitzgerald LA, Van Etten JL. 2002. Ornithine decarboxylase encoded by chlorella virus PBCV-1. Virology 301:165-75

129. Moroni A, Viscomi C, Sangiorgio V, Pagliuca C, Meckel T, et al. 2002. The short N-terminus is required for functional expression of the virus-encoded miniature $\mathrm{K}^{+}$channel Kcv. FEBS Lett. 530:65-69

130. Moss B. 1996. Poxviridae: the viruses and their replication. See Ref. 43a, pp. 2637-71

131. Mossi R, Hubscher U. 1998. Clamping down on clamps and clamp loaders - the eukaryotic replication factor C. Eur. J. Biochem. 254:209-16 
132. Müller DG, Kapp M, Knippers R. 1998. Viruses in marine brown algae. Adv. Virus Res. 50:49-67

133. Mushegian AR, Koonin EV. 1996. A minimal gene set for cellular life derived by comparison of complete bacterial genomes. Proc. Natl. Acad. Sci. USA 93:10268-73

133a. Muzzarelli R, Jeuniaux C, Gooday GW, eds. 1986. Chitin in Nature and Technology. New York: Plenum

134. Myllykallio H, Lipowski G, Leduc D, Filee J, Forterre P, Liebl U. 2002. An alternative flavin-dependent mechanism for thymidylate synthesis. Science 297:105-7

135. Nagasaki K, Ando M, Itakura S, Imai I, IshidaY. 1994.Viral mortality in the final stage of Heterosigma akashiwo Raphidophyceae red tide. J. Plankton Res. 16: 1595-99

136. Nagasaki K, Ando M, Itakura S, Imai I, Ishida Y. 1994. Virus-like particles in Heterosigma akashiwo Raphidophyceae: a possible red tide disintegration mechanism. Mar. Biol. 119:307-12

137. Nagasaki K, Tarutani K, Yamaguchi M. 1999. Growth characteristics of Heterosigma akashiwo virus and its possible use as a microbiological agent for red tide control. Appl. Environ. Microbiol. 65:898-902

138. Nakada Y, Jiang Y, Nishijyo T, Itoh Y, Lu C-D. 2001. Molecular characterization and regulation of the aguBA operon, responsible for agmatine utilization in Pseudomonas aeruginosa PAO1. J. Bacteriol. 183:6517-24

139. Nakai K, Kanehisa M. 1992. A knowledge base for predicting protein localization sites in eukaryotic cells. Genomics 14:897-911

140. Nandhagopal N, Simpson A, Gurnon JR, Yan X, Baker TS, et al. 2002. The structure and evolution of the major capsid protein of a large, lipid-containing DNA virus. Proc. Natl. Acad. Sci. USA 99:14758-63

141. Nassel DR. 1999. Histamine in the brain of insects: a review. Micros. Res. Tech. 44:121-36

142. Nelson M, Burbank DE, Van Etten JL. 1998. Chlorella viruses encode multiple DNA methyltransferases. Biol. Chem. 379:423-28

143. Nelson M, Zhang Y, Van Etten JL. 1993.DNAmethyltransferases andDNA site-specific endonucleases encoded by chlorella viruses. In DNA Methylation: Molecular Biology and Biological Significance, ed. JP Jost, HP Saluz, pp. 186- 211. Basel: Birkhauser Verlag

144. Nietfeldt JW, Lee K, Van Etten JL. 1992. Chlorella virusPBCV-1 replication is not affected by cytoskeletal disruptors. Intervirology 33:116-20

145. Nishida K, Kawasaki T, Fujie M, Usami S, Yamada T. 1999. Aminoacylation of tRNAs encoded by chlorella virus CVK2. Virology 263:220-29

146. Nishida K, Kimura Y, Kawasaki T, Fujie M, Yamada T. 1999. Genetic variation of chlorella viruses: variable regions localized on the CVK2 genomic DNA. Virology 255:376-84

147. Nishida K, Suzuki S, Kimura Y, Nomura N, Fujie M, Yamada T. 1998. Group I introns found in chlorella viruses: biological implications. Virology 242:319-26

148. Oh-Hama T, Miyachi S. 1988. In Microalgal Biotechnology, ed. LJ Borowitzka, MA Borowitzka, pp. 3-26. Cambridge: Cambridge Univ. Press

149. Olofsson S, Hansen JES. 1998. Host cell glycosylation of viral glycoproteins: a battlefield for host defence and viral resistance. Scand. J. Infect Dis. 30:435-40

150. Peters LL, Lux SE. 1993. Ankyrins: structure and function in normal cells and hereditary spherocytes. Semin. Hematol. 30:85-118

151. Petrik DT, Iseli A, Montelone BA, Van Etten JL, Clem RJ. 2003. Improving baculovirus 
resistance to UV inactivation: increased virulence resulting from expression of a DNA repair enzyme. J. Invert. Pathol. 82:50-56

152. Pisani FM, DeFelice M, Carpentieri F, Rossi M. 2000. Biochemical characterization of a clamp-loader complex homologous to eukaryotic replication factor $\mathrm{C}$ from the hyperthermophilic archaeon Sulfolobus solfataricus. J. Mol. Biol. 301:61-73

153. Plugge B, Gazzarrini S, Nelson M, Cerana R, Van Etten JL, et al. 2000. A potassium channel protein encoded by chlorella virus PBCV-1. Science 287: 1641-44

154. Posfai J, Bhagwat AS, Posfai G, Roberts RJ. 1989. Predictive motifs derived from cytosine methyltransferases. Nucleic Acids Res. 17:2421-35

155. Que Q, Li Y,Wang IN, Lane LC, Chaney WG, Van Etten JL. 1994. Protein glycosylation and myristylation in chlorella virus PBCV-1 and its antigenic variants. Virology 203:320-27

156. Que Q, Van Etten JL. 1995. Characterization of a protein kinase gene from two chlorella viruses. Virus Res. 35:291-305

157. Que Q, Zhang Y, Nelson M, Ropp S, Burbank DE, Van Etten JL. 1997. Chlorella virus SC-1A encodes five functional and one nonfunctional DNA methyltransferases. Gene 190:237-44

158. Raetz CR, Whitfield C. 2002. Lipopolysaccharide endotoxins. Annu. Rev. Biochem. 71:635-700

159. Reisser W. 1987. Naturally occurring and artificially established associations of ciliates and algae. Ann. NY Acad. Sci. 503:316-29

160. Reisser W, ed. 1992. Algae and Symbioses. Bristol, UK: Biopress. 746 pp.

161. Reisser W, Burbank DE, Meints RH, Becker B, Van Etten JL. 1991. Viruses distinguish symbiotic Chlorella spp. of Paramecium bursaria. Endocytobiosis Cell Res. 7:245-51

162. Reisser W, Burbank DE, Meints SM, Meints RH, Becker B, Van Etten JL. 1988. A comparison of viruses infecting two different chlorella-like green algae. Virology 167:143-49

163. Reisser W, Kapaun E. 1991. Entry of a chlorella-virus into its host cell. J. Phycol. 27:609-13

164. Reuter G, Gabius HJ. 1999. Eukaryotic glycosylation: whim of nature or multipurpose tool. Cell Mol. Life Sci. 55:368- 422

165. Rohozinski J, Girton LE, Van Etten JL. 1989. Chlorella viruses contain linear nonpermuted double-stranded DNA genomes with covalently closed hairpin ends. Virology 168:363-69

166. Rossmann MG, Johnson JE. 1989. Icosahedral RNA virus structure. Annu. Rev. Biochem. 58:533-73

167. Royce CL, Pardy RL. 1996. Endotoxinlike properties of an extract from a symbiotic, eukaryotic chlorella-like green alga. J. Endotoxin Res. 3:437-44

168. Sandaa RA, Heldal M, Catsberg T, Thyrhaug R, Bratbak G. 2002. Isolation and characterization of two viruses with large genome size infecting Chrysochromulina ericina (Prymnesiophyceae) and Pyramimonas orientalis (Prasinophyceae). Virology 290:272-80

169. Schopf JW. 1999. Cradle of Life. Princeton NJ: Princeton Univ. Press. 367 pp.

170. Schuster AM, Girton L, Burbank DE, Van Etten JL. 1986. Infection of a chlorella-like alga with the virus PBCV-1: transcriptional studies. Virology 148:181-89

171. Schuster AM, Graves M, Korth K, Ziegelbein M, Brumbaugh J, et al. 1990. Transcription and sequence studies of a $4.3 \mathrm{kbp}$ fragment from a dsDNA eukaryotic algal virus. Virology 176:515-23 
172. Seaton GR, Lee K, Rohozinski J. 1995. Photosynthetic shutdown in Chlorella NC64A associated with the infection cycle of Paramecium bursaria chlorella virus-1. Plant Physiol. 108:1431- 38

173. Senkevich TG, Bugert JJ, Sisler JR, Koonin EV, Darai G, Moss B. 1996. Genome sequence of a human tumorigenic poxvirus: prediction of specific host response-evasion genes. Science 273:813-16

174. Senkevich TG, White CL, Koonin EV, Moss B. 2000. A viral member of the ERV1/ ALR protein family participates in a cytoplasmic pathway of disulfide bond formation. Proc. Natl. Acad. Sci. USA 97:12068-73

175. Shchelkunov SN, Totmenin AV. 1995. Two types of deletions in orthopoxvirus genomes. Virus Genes 9:231-45

176. Sherman LA, Brown RM. 1978. Cyanophages and viruses of eukaryotic algae. In Comprehensive Virology, ed. H Fraenkel-Conrat, RR Wagner, 12: 145-234. New York: Plenum

177. Shihra I, Krauss RW. 1965. Chlorella Physiology and Taxonomy of Forty-One Isolates. College Park, MD: Univ. Maryland Press

178. Shuman S. 2000. Structure, mechanism, and evolution of the mRNA capping apparatus. Prog. Nucleic Acid Res. Mol. Biol. 66:1-40

179. Sieburth JM, Johnson PW, Hargraves PE. 1988. Ultrastructure and ecology of Aureococcus anophagofferens gen. set. sp. nov. Chrysophyceae: the dominant picoplankton during a bloom in Narragansett Bay, Rhode Island, summer 1985. J. Phycol. 24:416-25

180. Skrdla MP, Burbank DE, Xia Y, Meints RH, Van Etten JL. 1984. Structural proteins and lipids in a virus, PBCV-1, which replicates in a chlorella-like alga. Virology 135:308-15

181. Songsri P, Hamazaki T, Ishikawa Y, Yamada T. 1995. Large deletions in the genome of chlorella virus CVK1. Virology 214:405-12

182. Songsri P, Hiramatsu M, Fujie M, Yamada T. 1997. Proteolytic processing of chlorella virusCVK2capsid proteins. Virology 227:252-54

183. Sriskanda V, Shuman S. 2002. Role of nucleotidyltransferase motifs I, III and IV in the catalysis of phosphodiester bond formation by chlorella virus DNA ligase. Nucleic Acids Res. 30:903- 11

184. Strasser P, Zhang YP, Rohozinski J, Van Etten JL. 1991. The termini of the chlorella virusPBCV-1 genome are identical 2.2-kbp inverted repeats. Virology 180:763-69

185. Suda K, Tanji Y, Hori K, Unno H. 1999. Evidence for a novel chlorella virus encoded alginate lyase. FEMS Microbiol. Lett. 180:45-53

186. Sugimoto I, Hiramatsu S, Murakami D, Fujie M, Usami S, Yamada T. 2000. Algal-lytic activities encoded by chlorella virus CVK2. Virology 277: 119-26

187. Sun L, Adams B, Gurnon JR, Ye Y, Van Etten JL. 1999. Characterization of two chitinase genes and one chitosanase gene encoded by chlorella virus PBCV-1. Virology 263:376-87

188. Sun L, Gurnon JR, Adams BJ, Graves MV, Van Etten JL. 2000. Characterization of a $\beta$ 1,3-glucanase encoded by chlorella virus PBCV-1. Virology 276:27-36

189. Sun L, LiY, McCullough AK,Wood TG, Lloyd RS, et al. 2000. Intron conservation in a UV-specific DNA repair gene encoded by chlorella viruses. J. Mol. Evol. 50:82-92

190. Suttle CA. 2000. Ecological, evolutionary, and geochemical consequences of viral infection of cyanobacteria and eukaryotic algae. In Viral Ecology, ed. C Hurst, pp. 24796. New York: Academic

191. Suttle CA, Chan AM. 1994. Dynamics and distribution of cyanophages and their effect on marine Synechococcus spp. Appl. Environ. Microbiol. 60:3167-74 
192. Suttle CA, Chen F. 1992. Mechanisms and rates of decay of marine viruses in seawater. Appl. Environ. Microbiol. 58:3721-29

193. Swaminathan N, George D, McMaster K, Szablewski J, Van Etten JL, Mead DA. 1994. Restriction generated oligonucleotides utilizing the two base recognition endonuclease CviJI*. Nucleic Acids Res. 22:1470-75

194. Takeda H. 1988. Classification of chlorella strains by cell wall sugar composition. Phytochemistry 27:3822-26

195. Takeda H. 1995. Cell wall composition and taxonomy of symbiotic chlorella from paramecium and acanthocystis. Phytochemistry 40:457-59

196. Tanner NK, Linder P. 2001. DexD/H box RNA helicases: from generic motors to specific dissociation functions. Mol. Cell 8:251-62

197. Tessman I. 1985. Genetic recombination of the DNA plant virus PBCV-1 in a chlorellalike alga. Virology 145:319-22

198. Tidona CA, Darai G. 1997. The complete DNA sequence of lymphocystis disease virus. Virology 230:207-16

199. Tonetti M, Zanardi D, Gurnon JR, Fruscione F, Armirotti A, et al. 2003. Paramecium bursaria Chlorella virus encodes two enzymes involved in the biosynthesis of GDP-Lfrucose and GDP-Drhamnose. J. Biol. Chem. 278:21559-65

200. Trench RK. 1979. The cell biology of plant-animal symbiosis. Annu. Rev. Plant Physiol. 30:485-531

201. Turner PC,MoyerRW. 1990. The molecular pathogenesis of poxviruses. Curr. Top. Microbiol. Immunol. 163:125-51

202. Tyms AS, Clarke JR, Ford L, Edoranta T. 1990. Polyamines and the growth of pathogenic viruses. In The Biology and Chemistry of Polyamines. ed. SH Goldenberg, JD Algaranti, pp. 121-33. Oxford: IRL Press

203. Van Etten JL. 2000. Phycodnaviridae. In Virus Taxonomy, Classification and Nomenclature of Viruses, 7th Rep., ed. MHV Van Regenmortel, CM Fauquet, DHL Bishop, EB Carstens, MK Estes, SM Lemon, J Maniloff, MA Mayo, DJ McGeoch, CR Pringle, RBWickner, pp. 183-93. San Diego: Academic

204. Van Etten JL, Burbank DE, Joshi J, Meints RH. 1984. DNA synthesis in a chlorella-like alga following infection with the virus PBCV-1. Virology 134: 443-49

205. Van Etten JL, Burbank DE, Meints RH. 1986. Replication of the algal virus PBCV-1 in UV-irradiated chlorella. Intervirology 26:115-20

206. Van Etten JL, Burbank DE, XiaY, Meints RH. 1983. Growth cycle of a virus, PBCV-1, that infects chlorella-like algae. Virology 126:117-25

207. Van Etten JL, Graves MV, Muller DG, Boland W, Delaroque N. 2002. Phycodnaviridae - large DNA algal viruses. Arch. Virology 147:1479-516

208. Van Etten JL, Lane LC, Meints RH. 1991. Viruses and viruslike particles of eukaryotic algae. Microbiol. Rev. 55: 586-620

209. Van Etten JL, Meints RH. 1999. Giant viruses infecting algae. Annu. Rev. Microbiol. 53:447-94

210. Van Etten JL, Meints RH, Burbank DE, Kuczmarski D, Cuppels DA, Lane LC. 1981. Isolation and characterization of a virus from the intracellular green alga symbiotic with Hydra viridis. Virology 113:704-11

211. Van Etten JL, Meints RH, Kuczmarski D, Burbank DE, Lee K. 1982. Viruses of symbiotic chlorella-like algae isolated from Paramecium bursaria and Hydra viridis. Proc. Natl. Acad. Sci. USA 79:3867-71 
212. Van Etten JL, Schuster AM, Girton L, Burbank DE, Swinton D, Hattman S. 1985. DNA methylation of viruses infecting a eukaryotic chlorella-like alga. Nucleic Acids Res. 13:3471-78

213. Van Etten JL, Schuster AM, Meints RH. 1988. Viruses of eukaryotic chlorellalike algae. In Viruses of Fungi and Simple Eukaryotes, ed. Y Koltin, MJ Leibowitz, pp. 411-28. New York: Marcel Dekker

214. Van Etten JL,Van Etten CH, Johnson JK, Burbank DE. 1985. A survey for viruses from fresh water that infect a eukaryotic chlorella-like green alga. Appl. Environ. Microbiol. 49:1326-28

215. van Hulten MC, Witteveldt J, Peters S, Kloosterboer N, Tarchini R, et al. 2001. The white spot syndrome virus DNA genome sequence. Virology 286:7-22

216. Villarreal LP. 1999. DNA viruses: their influence on host evolution. In Origin and Evolution ofViruses, ed,EDomingo, R Webster, JJ Holland, T Pickett, pp. 391-410. London: Academic

217. Villarreal LP, DeFilippis VR. 2000. A hypothesis for DNA viruses as the origin of eukaryotic replication proteins. J. Virol. 74:7079-84

218. Wang I-N, Smith D, Young R. 2000. Holins: the protein clocks of bacteriophage infections. Ann. Rev. Microbiol. 54:799-825.

219. Wang I-N, Li Y, Que Q, Bhattacharya M, Lane LC, et al. 1993. Evidence for virusencoded glycosylation specificity. Proc. Natl. Acad. Sci. USA 90:3840-44

220. Warbrick E. 2000. The puzzle ofPCNA's many partners. BioEssays 22:997-1006

221. Wiggins BA, Alexander M. 1985. Minimum bacterial density for bacteriophage replication: implications for significance of bacteriophages in natural ecosystems. Appl. Environ. Microbiol. 49:19-23

222. Wilson GG, Murray NE. 1991. Restriction and modification systems. Annu. Rev. Genet. 25:585-627

223. Wolf S, Maier I, Katsaros C,Müller DG. 1998. Virus assembly in Hincksia hincksiae (Ecocarpales, Phaeophyceae). An electron and fluorescence microscopic study. Protoplasma 203:153-67

224. Wommack KE, Colwell RR. 2000. Virioplankton: viruses in aquatic ecosystems. Microbiol. Mol. Biol. Rev. 64:69- 114

225. Xia Y, Burbank DE, Uher L, Rabussay D, Van Etten JL. 1986. Restriction endonuclease activity induced by PBCV-1 virus infection of a chlorella-like green alga. Mol. Cell. Biol. 6:1430-39

226. Xia Y, Burbank DE, Uher L, Rabussay D, Van Etten JL. 1987. IL-3A virus infection of a chlorella-like green alga induces a DNA restriction endonuclease with novel sequence specificity. Nucleic Acids Res. 15:6075-90

227. Xia Y, Morgan R, Schildkraut I, Van Etten JL. 1988.Asite-specific single strand endonuclease activity induced by NYs-1 virus infection of a chlorella-like green alga. $\mathrm{Nu}$ cleic Acids Res. 16:9477-87

228. Xia Y, Van Etten JL. 1986. DNA methyltransferase induced by PBCV-1 virus infection of a chlorella-like green alga. Mol. Cell. Biol. 6:1440-45

229. Xu M, Kladde MP, Van Etten JL, Simpson RT. 1998. Cloning, characterization, and expression of the gene coding for a cytosine-5-DNA methyltransferase recognizing GpC sites. Nucleic Acids Res. 26:3961-66

230. Yamada T, Fukuda T, Tamura K, Furukawa S, Songsri P. 1993. Expression of the gene encoding a translational elongation factor 3 homolog of chlorella virus CVK2. Virology 97:742-50 
231. Yamada T, Furukawa S, Hamazaki T, Songsri P. 1996. Characterization of DNAbinding proteins and protein kinase activities in chlorella virus CVK2. Virology 219:395-406

232. Yamada T, Higashiyama T. 1993. Characterization of the terminal inverted repeats and their neighboring tantem repeats in the chlorella CVK1 virus genome. Mol. Gen. Genet. 241:554- 63

233. Yamada T, Higashiyama T, Fukuda T, 1991. Screening of natural waters for viruses which infect chlorella cells. Appl. Environ. Microbiol. 57:3433-37

234. Yamada T, Hiramatsu S, Songsri P, Fujie M. 1997. Alternative expression of a chitosanase gene produces two different proteins in cells infected with chlorella virus CVK2. Virology 230:361-68

235. Yamada T, Sakaguchi K. 1982. Comparative studies on chlorella cell walls: induction of protoplast formation. Arch. Microbiol. 132:1013

236. Yamada T, Tamura K, Aimi T, Songsri P. 1994. Self-splicing group I introns in eukaryotic viruses. Nucleic Acids Res. 22:2532-37

237. Yan X, Olson NH, Van Etten JL, Bergoin M, Rossmann MG, Baker TS. 2000. Structure and assembly of large, lipidcontaining, dsDNA viruses. Nat. Struct. Biol. 7:101-3

238. Yanez RJ, Rodriguez JM, Nogal ML, Yuste L, Enriquez C, et al. 1995. Anaylsis of the complete nucleotide sequence of African swine fever virus. Virology 208:249-78

239. Zhang Y, Adams B, Sun L, Burbank DE, Van Etten JL. 2001. Intron conservation in the DNA polymerase gene encoded by chlorella viruses. Virology 285:313- 21

240. Zhang Y, Nelson M, Nietfeldt JW, Burbank DE, Van Etten JL. 1992. Characterization of chlorella virusPBCV-1 CviAII restriction and modification system. Nucleic Acids Res. 20:5351-56

241. Zhang Y, Nelson M, Nietfeldt J, Xia Y, Burbank DE, et al. 1998. Chlorella virus NY$2 \mathrm{~A}$ encodes at least twelve DNA endonuclease/ methyltransferase genes. Virology 240:366-75

242. Zhang Y, Nelson M, Van Etten JL. 1992. A single amino acid change restores DNAcytosine methyltransferase activity in a cloned chlorella virus pseudogene. Nucleic Acids Res. 20:1637-42

243. Zhang Y, Strasser P, Grabherr R, Van Etten JL. 1994. Hairpin loop structure at the termini of the chlorella virus PBCV-1 genome. Virology 202:1079-82 
Figure 1. (page 197) Three-dimensional image reconstruction of chlorella virus PBCV1 from cryoelectron micrographs. A. The virion capsid consists of 12 pentasymmetrons and 20 trisymmetrons. Five trisymmetrons are highlighted in the reconstruction (blue) and a single pentasymmetron is colored yellow. A pentavalent capsomer (white) lies at the center of each pentasymmetron. Each pentasymmetron consists of one pentamer plus 30 trimers. Eleven capsomers form the edge of each trisymmetron (black dots) and therefore each trisymmetron has 66 trimers. B. Cross-sectional view of PBCV-1 along the twofold axis. A lipid bilayer, like a railway track, exists beneath the capsid shell (magenta arrows). Magnified views at two- and fivefold axes (outlined in $B$ are shown in $C$ and $E$, respectively.) C. Connections occur between the capsid shell and the lipid bilayer (green arrows). D. The capsomers are interconnected by "cement" proteins (yellow arrows). The red arrow indicates the fiber-like structure in one trimeric capsomer. E. Dense material (blue arrow) (cell wall-digesting enzyme(s)?) is present at each vertex (red arrow) between the vertex and the membrane. F. Closeup view of a portion of a trisymmetron. Three of the 66 capsomers that comprise a trisymmetron have a kidney-shaped structure (green arrows). A cross section of one of these structures is seen in $D$ (red arrow). 

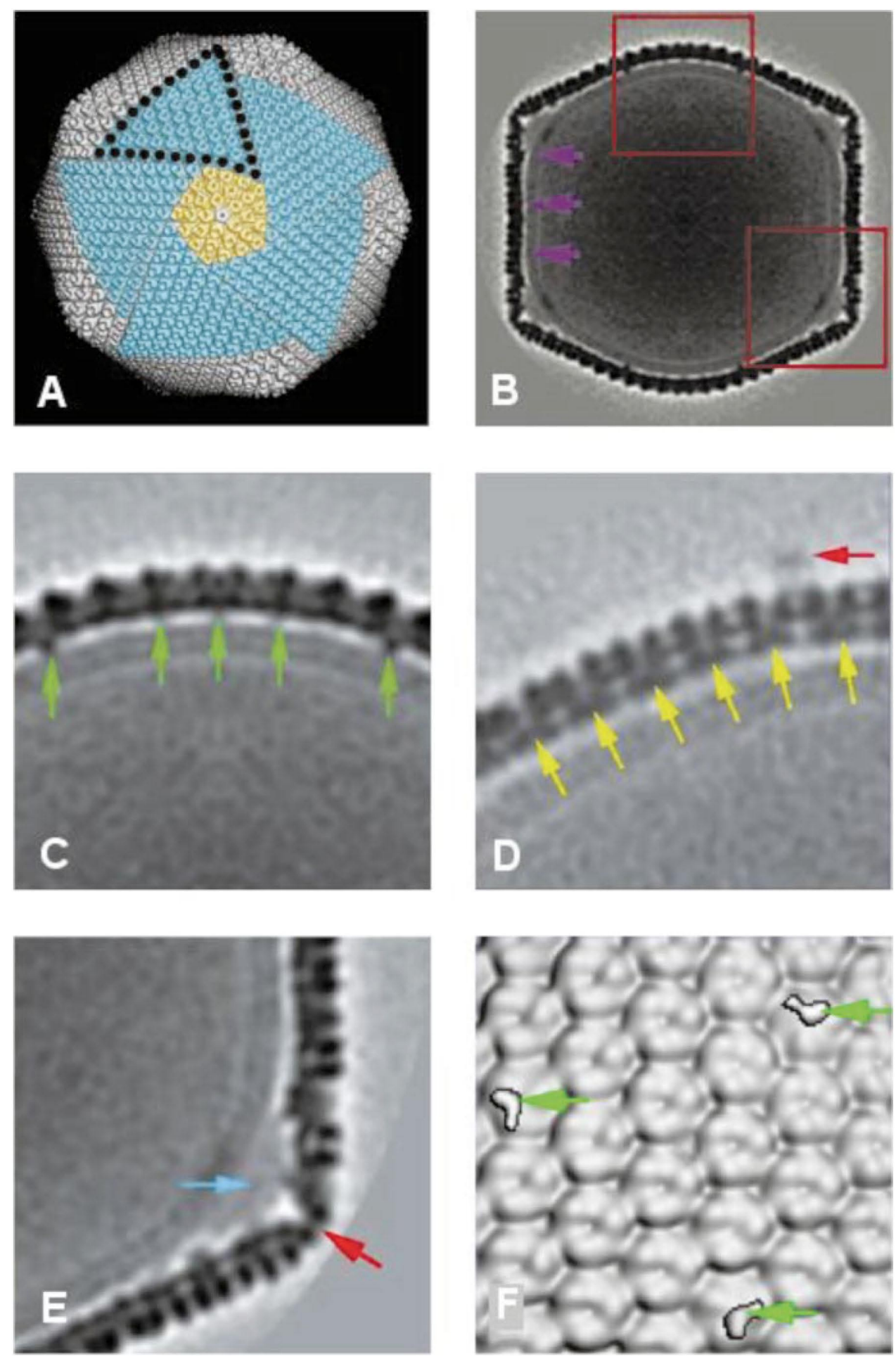